\title{
Release of nanomaterials from solid nanocomposites and consumer exposure assessment - a forward-looking review
}

\section{Mackevica, Aiga; Hansen, Steffen Foss}

\section{Published in:}

Nanotoxicology

Link to article, DOI:

$10.3109 / 17435390.2015 .1132346$

Publication date:

2016

Document Version

Peer reviewed version

Link back to DTU Orbit

Citation (APA):

Mackevica, A., \& Hansen, S. F. (2016). Release of nanomaterials from solid nanocomposites and consumer exposure assessment - a forward-looking review. Nanotoxicology, 10(6), 641-653.

https://doi.org/10.3109/17435390.2015.1132346

\section{General rights}

Copyright and moral rights for the publications made accessible in the public portal are retained by the authors and/or other copyright owners and it is a condition of accessing publications that users recognise and abide by the legal requirements associated with these rights.

- Users may download and print one copy of any publication from the public portal for the purpose of private study or research.

- You may not further distribute the material or use it for any profit-making activity or commercial gain

- You may freely distribute the URL identifying the publication in the public portal

If you believe that this document breaches copyright please contact us providing details, and we will remove access to the work immediately and investigate your claim 


\section{Release of nanomaterials from solid nanocomposites and consumer exposure assessment - A forward-looking review}

Aiga Mackevica, ${ }^{*}$ Steffen Foss Hansen

Department of Environmental Engineering, Technical University of Denmark, Kgs. Lyngby, DK-2800, Denmark

*Corresponding author (e-mail: aima@env.dtu.dk, phone: +45 4525 1477)

\section{Abstract}

The European chemical legislation requires manufacturers and importers of chemicals to do consumer exposure assessment when the chemical has certain hazards associated to it (e.g. explosive, carcinogenicity, hazardous to the aquatic environment), but the question is how this obligation can be met in light of the scientific uncertainty and technical challenges related to exposure assessment of nanomaterials. In this paper, we investigate to what extent the information and data in the literature can be used to perform consumer exposure assessment according to the REACH requirements and we identify and discuss the key data needs and provide recommendations for consumer exposure assessment of nanomaterials. In total, we identified 76 studies of relevance. Most studies have analyzed the release of $\mathrm{Ag}$ and $\mathrm{TiO}_{2}$ from textiles and paints, and $\mathrm{CNT}$ and $\mathrm{SiO}_{2}$ from nanocomposites. Less than half of the studies report their findings in a format that can be used for exposure assessment under REACH, and most do not include characterization of the released particles. Although inhalation, dermal and oral exposures can be derived using the guidelines on how to complete consumer exposure assessments under REACH, it is clear that the equations are not developed to take the unique properties of nanomaterials into consideration. Future research is therefore needed on developing more generalized methods for representing nanomaterial release from different product groups at relevant environmental conditions. This includes improving the analytical methods for determining nanomaterial alteration and transformation, as well as 
quantification, which could subsequently lead to more nano-specific consumer exposure assessment models.

\section{Keywords}

Nanomaterials, nanoparticles, consumer products, nanocomposites, release, consumer exposure, consumer exposure assessment, $\mathrm{REACH}$, regulation, risk assessment 


\section{Table of contents}

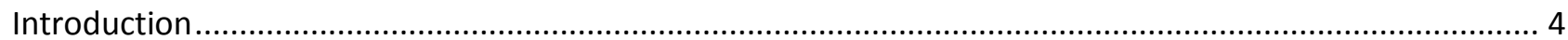

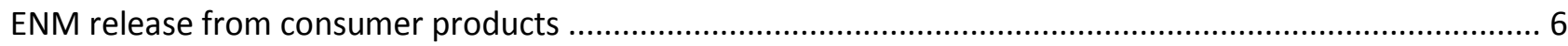

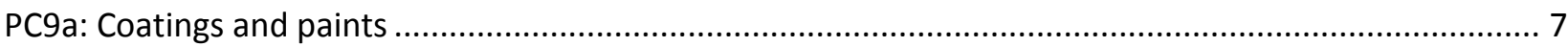

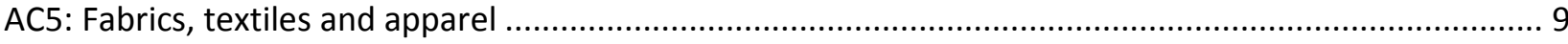

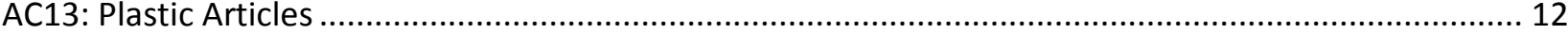

AC 4: Stone, plaster, cement, glass and ceramic articles ................................................................. 14

Consumer exposure assessment according to REACH .......................................................................... 15

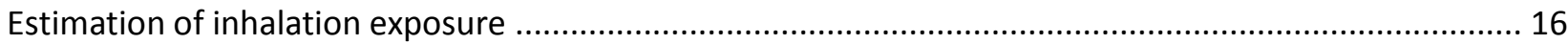

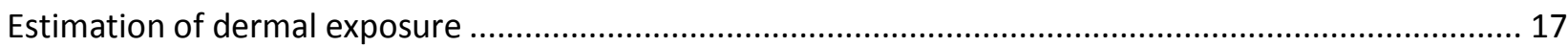

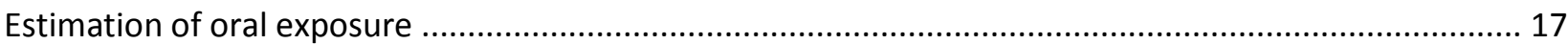

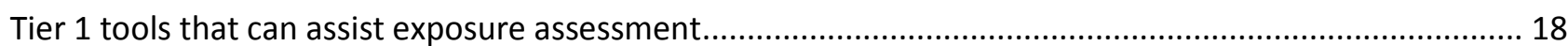

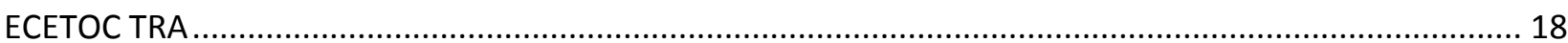

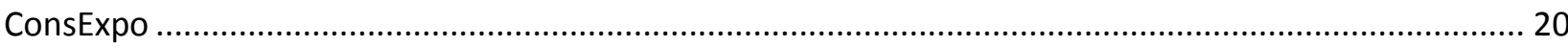

Applying REACH algorithms to ENM release literature ............................................................................ 21

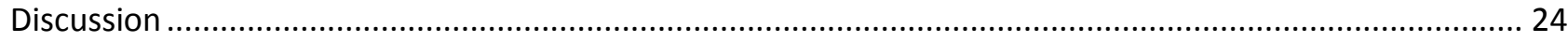

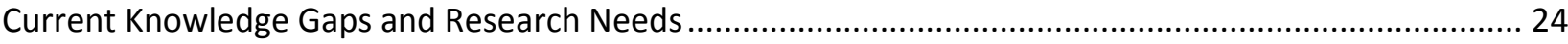

Exposure Estimations and Challenges when Using ECHA's R.15 Guidance for ENMs............................... 26

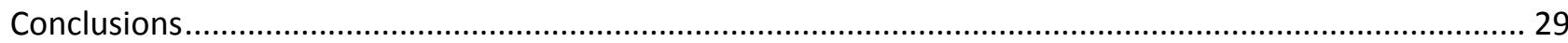

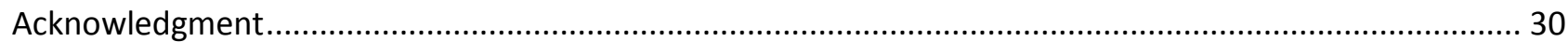

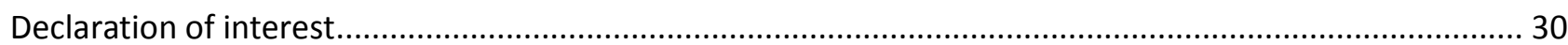

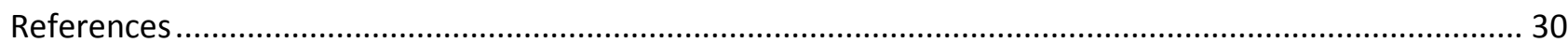

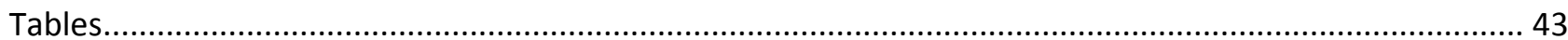

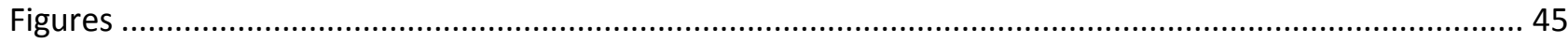

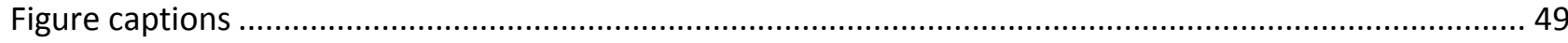




\section{Introduction}

Engineered nanomaterials (ENMs) are used in a wide range of applications and consumer products, such as medical products, cosmetics, textiles, paints, food packaging and personal care products (The Nanodatabase, 2015). In the last decade the production and use of ENM-containing products has increased dramatically, and that has raised concern about potential impacts of ENMs on human health and environment (Som et al., 2010; Nowack, 2009; Klaine et al., 2008; WHO, 2013). Whether the substance is dangerous involves determining both its potential toxicity and also the possibility and degree of exposure (Wiesner et al., 2006; Som et al., 2010). Both toxicity and exposure are relevant parameters for risk assessment of any chemical substance, including ENMs. Currently, there are a number of major knowledge gaps regarding the health and environmental risks posed by ENMs (Handy et al., 2008; Klaine et al., 2008; Nowack and Bucheli, 2007; Wiesner et al., 2009; WHO, 2013; Hansen et al., 2013; Lynch, 2014). A substantial amount of research has been done investigating the potential toxicological impacts of ENMs on humans and the environment (Nowack, 2009; Hansen et al., 2013; WHO, 2013), but only recently the necessity for obtaining data on ENM release during use been recognized, which would help characterize, for instance, consumer exposure (Ostertag and Hasing, 2008; Lynch, 2014; Ganzleben and Hansen, 2012).

The European Union (EU) chemical legislation known as REACH (Regulation on Registration, Evaluation, Authorisation and Restriction of Chemicals) requires manufacturers and importers of chemicals to do a consumer exposure assessment if the chemical is classified as either having a number physical hazards associated to it (e.g. explosive, flammable); human hazards (e.g. carcinogenicity, reproductive toxicity) and/or is classified as hazardous to the aquatic environment or the ozone layer (European Parliament and the Council of the European Union, 2006; European Parliament and the Council of the European Union, 2008). Under REACH, exposure assessment consists of two elements: 1) The generation of exposure scenario(s), which includes identification of relevant uses and exposure categories and 2) Exposure estimation (European Parliament and the Council of the European Union, 2006). 
While worker exposure and estimation of environmental exposure to ENMs has received quite some attention (Lynch, 2014), estimation of consumer exposure to ENMs is still limited. The question remains open how this obligation can be met in light of the scientific uncertainty and technical challenges related to exposure assessment of ENMs.

It has been recognized that the wide variety of available consumer products, the diverse group of consumers, which use products in different ways and the lack of measured exposure data for all compounds in the product for all conceivable exposure scenarios and all consumer groups, makes consumer exposure assessment especially challenging. In order to assess consumer exposure, it is important to start with a clearly defined exposure scenario and investigate who is exposed, how often and via which routes the exposure could take place, etc. However, such information is very seldom available (Delmaar et al., 2005) and it is unclear whether such information is available at all when it comes to ENMs.

In this paper, we first present a review of experimental studies published regarding the release from nanoenabled solid consumer products and nanocomposites. Thereafter, we will introduce the requirements that the EU chemical legislation puts on manufacturers and importers of chemicals when it comes to consumer exposure assessment. The objective of the review is threefold: 1) to provide an up-to-date literature overview of the available literature on release from ENM-containing solid consumer products; 2) identifying the advantages and shortcomings for existing experimental setups when it comes to using the data for consumer exposure assessment; and 3) apply REACH algorithms for consumer exposure assessment and provide recommendations for future work regarding ENM-specific consumer exposure assessment.

Following the two-step exposure assessment approach outline by $\mathrm{REACH}$, this review first organizes the identified studies on the ENM release according to the product group they are addressing. Then, we highlight the release scenarios and methods that have been applied, noting the analytical methods that have been used for characterization of the pristine ENMs, the ENMs in the product matrix and/or the released forms, as well as the most relevant findings of the studies. One of the main concerns is the release 
of ENMs during use of ENM containing products (Gottschalk and Nowack, 2011; Nowack and Bucheli, 2007) and hence focus will be on studies that have investigated the emissions of ENMs from consumer products noting various consumer-relevant use scenarios that could lead to exposure.

In order to complete the second exposure assessment step of REACH we used the information gathered in the first step to test the applicability of a range of Tier 1 and Higher Tier exposure assessment tools and we investigate to what extent information and data in the open literature can be used to fulfill the REACH requirements. Finally, we identify and discuss key knowledge and data gaps and provide recommendations.

\section{ENM release from consumer products}

Even though the release of ENMs from consumer products is a relevant factor for risk assessment, there is a distinct lack of analytical information available regarding the potential release (Gottschalk and Nowack, 2011). To identify the studies describing the release of ENMs from consumer products, we performed a literature search using ISI Web of Knowledge and cross-referencing with such keywords as: nanomaterials, nanoparticles in combination with consumer products and release. After identifying the studies investigating release from consumer products containing ENMs embedded in solid matrix, these studies were grouped according to the nanomaterial composition noting the techniques used for characterization of ENMs both in product matrix and in the released form (Table S1 in Supporting Information).

Quite recently Froggett et al. (2014) published a review on release of nanomaterials from solid nanocomposites using PubMed and Chemical Abstract databases using search terms: nanoparticle, nanomaterial and release. Until 2013, they identified 54 articles that describe nanomaterial release (Froggett et al., 2014). In this review, apart from identifying studies on release from nano-enabled products, we have attempted to present their findings in a quantitative manner, noting the content and size of nanomaterial in the product, as well as the amount and size of released nanomaterials, if reported (Table S1 in Supporting Information). These data are intended to be used further on for the exposure 
assessment according to REACH. To the best of our knowledge, this is the first review which is not only addressing the nanomaterial release from solid nanocomposites, but also compiling the published studies by noting their findings and using them further to perform consumer exposure assessment.

In total, we identified 76 publications of relevance when it comes to estimating consumer exposure, 16 of which have been published in 2014. The general trend is that the number of publications regarding ENM release has increased during the last 5 years (Figure 1). The most studied ENMs include $\mathrm{Ag}$ and $\mathrm{TiO}_{2} \mathrm{NPs}$, CNTs and $\mathrm{SiO}_{2}$ (Figure 2).

Most publications regarding ENM release are focusing on most widely used ENMs, such as $\mathrm{Ag}, \mathrm{TiO}_{2}, \mathrm{CNTs}$, and $\mathrm{SiO}_{2}$, and only a few product groups, namely: fabrics, paints or coatings, and polymers (Figure 3). REACH guidance on information requirements and chemical safety assessment Chapter R.12 provides a pick-list of Product Categories and Article Categories which describes uses regulated by REACH and which are generally considered to potentially result in significant consumer exposure. Examples of Product Categories (PC) include PC1: Adhesives, sealants and PC35: Washing and cleaning products whereas Article Categories (AC) include AC5: Fabrics, textiles and apparel and AC 13: Plastic articles. This review is organized grouping the release studies based on the ENM release according to the REACH Product and Article Categories and for each study we highlight the experimental setup and methods that have been applied, noting the analytical methods that have been used for characterization of pristine ENMs, ENMs in the product matrix or the released forms, noting the most relevant findings of the studies (Table S1 in the Supporting Information).

\section{PC9a: Coatings and paints}

ENMs such as e.g. Ag, $\mathrm{TiO}_{2}$ or $\mathrm{SiO}_{2}$ are added to paints and coatings for various reasons. Ag nanoparticles (NPs) are used as additives due to their anti-microbial properties, and AgNP-containing paints are therefore regarded as an important source of AgNPs released into the aquatic environment (Kaegi et al., 2010). $\mathrm{TiO}_{2}$ NPs are widely being used as photocatalysts in surface coatings and paints, and as a pigment to increase 
whiteness (Varner et al., 2010), whereas $\mathrm{SiO}_{2}$ NPs gives surface coatings hydrophobic properties and improves hardness and scratch resistance (Zhou et al., 2004). Studies addressing ENM release from paints have chosen various experimental setups to assess the release. One of the common approaches is weathering using light and/or water, to simulate outdoor conditions (Al-Kattan et al., 2014; Kaegi et al., 2010; Olabarrieta et al., 2012; Al-Kattan et al., 2013; Kaegi et al., 2008; Zuin et al., 2014). Kaegi et al. (2010) conducted an experiment to quantify the release of AgNPs from outdoor facades, using a facade panel painted with AgNP containing paint. Another study by Kaegi et al. (2008) investigated the release of $\mathrm{TiO}_{2}$ from paints applied to exterior facades, during two years of exposure to ambient weather conditions. In both cases there was some $\mathrm{TiO}_{2}$ release observed.

Weathering experiments can provide a good indication for what is happening when ENM-containing paints are applied to outdoor facades, however, it is difficult to quantify releases on a bigger scale. There are numerous things that have to be considered, such as the release of ENMs when the paintbrushes are being washed and the amount of paint applied per unit area, as well as environmental factors such as temperature, humidity, sunlight, wind and rain, which will highly influence ENM release kinetics (Kaegi et al., 2008).

Another release scenario addressing ENM release from paints and coatings is sanding and abrasion processes, which are more relevant for inhalation exposure assessment Hsu and Chein (2007) conducted a study to investigate release of $\mathrm{TiO}_{2} \mathrm{NPs}$ from surface coatings on polymer, wood and tile. The experiment took place in a simulation box, where materials were exposed to UV lamps, a fan and rubber knife to simulate sunlight, wind and human contact, respectively. The treatment with UV light increased the release of particles in sizes of $<200 \mathrm{~nm}$ from the coated materials. For polymer and wood samples the emissions decreased significantly after 60 and $90 \mathrm{~min}$, respectively. For the tile sample the release rate continued to increase after $2 \mathrm{~h}$ of testing, and tile was shown to have the highest emissions in comparison to coated 
polymer and wood (Hsu and Chein, 2007). However, this study did not address the presence of ENM and composition of the released particles.

The release due to sanding has been investigated for paints containing different $\mathrm{ENMs}$, such as $\mathrm{TiO}_{2}$, carbon black or $\mathrm{SiO}_{2}$ (Koponen et al., 2009; Koponen et al., 2011; Saber et al., 2012), $\mathrm{ZnO}$ and $\mathrm{Fe}_{2} \mathrm{O}_{3}$ (Gohler et al., 2010), $\mathrm{TiO}_{2}$, carbon black, $\mathrm{Fe}_{2} \mathrm{O}_{3}$ and $\mathrm{Al}_{2} \mathrm{O}_{3}$ (Göhler et al., 2013), where released particles have been analyzed by airborne particle counters (Condensation Particle Counter (CPC), Aerosol Particle Sizer (APS) or Scanning Mobility Particle Sizer (SMPS)) and chemical composition has either not been addressed or ENM presence has been investigated by Transmission Electron Microscopy (TEM) or Scanning Electron Microscopy (SEM) analysis. Most of these studies have concluded that there is no systematic difference in released particle number and size depending on the presence of ENMs in paint (Koponen et al., 2009; Koponen et al., 2011; Gohler et al., 2010; Saber et al., 2012). Some studies found ENMs embedded in paint matrix of released particles, such as Gohler et al. (2010) with $\mathrm{ZnO}$ and $\mathrm{Fe}_{2} \mathrm{O}_{3}$ NPs and Saber et al. (2012) with $\mathrm{TiO}_{2}$, carbon black and $\mathrm{SiO}_{2} \mathrm{NPs}$.

\section{AC5: Fabrics, textiles and apparel}

The most commonly addressed ENM as an additive in fabrics is $\mathrm{Ag}$, as it has become very popular due to the functionality of destroying odors and fighting bacterial infections, which is why Ag NPs are used in socks, t-shirts, medical masks, underwear, slippers, among others (Luoma and Rainbow, 2008). Recent studies have shown that Ag NP-containing textiles can release significant quantities of Ag in water (Benn and Westerhoff, 2008; Benn et al., 2010; Pasricha et al., 2012), washing liquid (Geranio et al., 2009; Lorenz et al., 2012; Impellitteri et al., 2009), and artificial sweat (Kulthong et al., 2010; Geranio et al., 2009; von Goetz et al., 2013a).

Several studies have been conducted to investigate ENM release from Ag NP-containing commercial textiles in water (Pasricha et al., 2012; Benn et al., 2010; Benn and Westerhoff, 2008). These studies are useful for confirming (for instance, by TEM imaging) that $\mathrm{Ag}$ is actually released and that $\mathrm{Ag}$ is present both as 
particles and ions in the solution. However, for quantitative and more illustrative results of release from consumer products, it is more useful to consider experiments with textiles in detergent solution, as this represents the process of washing the textiles. Some reports have used experimental setup relevant for fabric washing conditions (Geranio et al., 2009; Impellitteri et al., 2009; Lorenz et al., 2012; Mitrano et al., 2014). One of these studies applied detergent solution and stirring to imitate washing conditions, and the aim of the analysis was to characterize the released Ag speciation. After treatment with detergent a significant amount of $\mathrm{AgNPs}$ (more than $50 \%$ ) were converted to $\mathrm{AgCl}$, but unfortunately the total loss of $\mathrm{Ag}$ was not quantified by this study (Impellitteri et al., 2009). The other three studies used washing machines for the release experiments. One of them (Geranio et al., 2009) showed that there was little dissolution of $\mathrm{Ag}$ at $\mathrm{pH} 10$ and under normal washing conditions, whereas the dissolution was 10 times higher at $\mathrm{pH}$ 7. It was also stated that bleaching agents greatly increase the dissolution rates. However, the amount leached from the textiles was shown to be dependent on the manufacturing process, i.e. how the $\mathrm{Ag}$ was embedded in the fabric, leading to varying amounts of $\mathrm{Ag}$ released during first washing (from $<1 \%$ to $45 \%$ of the initial amount) (Geranio et al., 2009). Another study also detected leaching silver from various commercial textiles in the first washing/rinsing cycle (14.8-23.5\% of the initial amount), but mostly in agglomerated AgNP form (> $450 \mathrm{~nm}$ ) (Lorenz et al., 2012). Mitrano et al. (2014) findings showed that some dissolved silver was released from textiles during washing and in many cases ionic $\mathrm{Ag}$ had undergone transformation to form $\mathrm{Ag}^{0}, \mathrm{AgCl}$ or AgS particles (Mitrano et al., 2014). Studies like these are able to provide evidence of AgNP release in the wastewater from different AgNP-containing textiles, but the data is not representative for the emissions of Ag after repeated washing cycles (Geranio et al., 2009).

A number of studies have attempted to mimic one of the possible real-life scenarios of nano-Ag textile use by immersing the fabrics into artificial sweat at body temperature (Kulthong et al., 2010; von Goetz et al., 2013a; Yan et al., 2012; Stefaniak et al., 2014). The quantities of Ag released varied substantially for different fabrics and $\mathrm{pH}$ values, and was most likely dependent on the amounts of silver in fabrics, the fabric quality and the composition and pH of artificial sweat applied. In the study by Kulthong et al. (2010) 
the $\mathrm{pH}$ of sweat solutions was ranging from 4.3 to 8 , and lowest release was observed at $\mathrm{pH} 5.5$, which is close to $\mathrm{pH}$ of normal skin, whereas highest $\mathrm{Ag}$ release occurred at $\mathrm{pH}$ of 6.5 . This study tested 4 fabrics that were AgNP-treated in the lab, which all released considerable amounts of Ag in artificial sweat, and 6 commercial fabrics, out of which only 3 contained detectable amounts of silver and only two of them released detectable amounts of Ag. Also, initial silver content and the relative amount released for the labmade fabrics was considerably higher than detected in commercial fabrics (Kulthong et al., 2010).

Hedberg et al. (2014) used a different approach to address the Ag release from textiles in real life scenarios, exposing AgNP impregnated textiles to artificial sweat, laundry detergent and water solution in sequential and separate exposures. Their findings showed that $\mathrm{Ag}$ release from sequential exposures was by approximately a factor of 2 lower than the sum of release from separate exposures, which illustrates the importance of choosing an experimental setup to mimic the real world scenarios of textile use (Hedberg et al., 2014).

Only one study has addressed the release of $\mathrm{TiO}_{2}$ from textiles. Windler et al. (2012) analyzed emissions of $\mathrm{TiO}_{2}$ from six different textiles during washing and rinsing. The textiles contained significant amounts of $\mathrm{Ti}$ (from 0.2 to $0.9 \%$ ), but the presence of Ti could not be directly correlated to the content of $\mathrm{TiO}_{2} \mathrm{ENM}$ because of the lack of data from the manufacturers. However, regardless of whether the $\mathrm{TiO}_{2} \mathrm{NPs}$ have been added to textiles, the emissions showed that $\mathrm{TiO}_{2}$ was released in nanoparticulate range, mostly in form of agglomerates (confirmed by electron microscopy). The total Ti released varied between 0.01 to $0.06 \%$ of the total content in the fabric in one wash cycle, showing that $\mathrm{TiO}_{2}$ was strongly bound to the textile fiber matrix (Windler et al., 2012).

In general, all the experiments conducted with textiles provide information relevant for investigating whether or not the ENMs incorporated into textile can be released, but each one of them seems to cover only a very small part of the life-cycle of the corresponding product. This makes it difficult to extrapolate the release over the whole use phase. For example, washing the textile for the first time (Lorenz et al., 
2012; Geranio et al., 2009; Impellitteri et al., 2009) is not a representative event for the whole period of use of the product, and such is the case also for immersing never washed textiles into artificial sweat (Kulthong et al., 2010; von Goetz et al., 2013a; Yan et al., 2012).

\section{AC13: Plastic Articles}

Investigations of the release from nanomaterial containing polymer composites have mostly focused on $\mathrm{CNT}, \mathrm{SiO}_{2}$ and $\mathrm{Ag}$ release. Because of the antimicrobial properties of AgNPs, they are applied as inner coatings for various food storage containers, such as plastic bags or boxes to keep the food fresh longer (The Project on Emerging Nanotechnologies (PEN), 2013). Several studies have attempted to characterize and quantify the silver content in such products (von Goetz et al., 2013b; Huang et al., 2011), as well as determine the release of $\mathrm{Ag}$ in various food simulants (Huang et al., 2011; von Goetz et al., 2013b; Hauri and Niece, 2011).

A brief report by Huang et al. (2011) was one of the first publications addressing silver release from food storage containers. They used commercially available polyethylene bags and exposed them to different food simulants - deionized water, $4 \%$ acetic acid, $95 \%$ ethanol and hexane for 15 days at 25 to $50^{\circ} \mathrm{C}$. Analysis by Atomic Absorption Spectroscopy (AAS) proved presence of Ag in plastics and SEM coupled with Energy-Dispersive X-Ray Spectroscopy (EDS) showed that AgNPs could be found in the plastics. Also SEMEDS analysis after the test indicated that AgNPs have migrated into food simulants with particle sizes below $300 \mathrm{~nm}$. General trend was that release rates were increasing with higher temperatures and longer storage time (Huang et al., 2011). Another study (a student experiment) used commercially available plastic food containers that contained $\mathrm{Ag}$ and also found that acetic acid results in higher release rates in comparison to ethanol or distilled water, however, they did not quantify the initial Ag content of the containers or use any control as reference (Hauri and Niece, 2011). Von Goetz et al. (2013b) and Artiaga et al. (2014) had also chosen commercially available food storage materials for their migration experiments sharing a similar test setup, choosing instead of using food containers intact, having them cut in pieces and exposed to food 
simulants. Von Goetz et al. (2013b) showed that migration rates were considerably higher if the food containers were kept intact, raising doubts about the validity of the data from the shredded samples. However, all four aforementioned studies have something in common - the highest migration rates are observed when using acetic acid as a food simulant, which is probably because from all the applied migration solutions, acetic acid has the lowest $\mathrm{pH}$ which facilitates $\mathrm{Ag}$ nanoparticle dissolution (Liu and Hurt, 2010). Unlike the other studies, von Goetz et al (2013b) considered the multiple use scenario, measuring Ag release also for second and third use cycle, which showed that the Ag migration dropped by a factor up to 10. The overall conclusion from all the experiments was that consumer exposure is negligible, as the amounts leached from the food containers are very low (in magnitudes of $\mathrm{ng} / \mathrm{cm}^{2}$ ). However, around $12 \%$ of the total Ag released was in NP form, which could have different effects compared to ionic silver, therefore the question remains open whether or not the $\mathrm{Ag}$ release rates correspond to a safe background level (von Goetz et al., 2013b). Echegoyen and Nerin (2013) also tested commercially available food containers for release in multiple use cycles. Their findings showed that total Ag migration was decreasing with each cycle.

In two separate studies, Cushen et al. conducted migration studies from lab-made polymer films containing Ag (Cushen et al., 2013), and Ag and CuO (Cushen et al., 2014b) NPs into boneless chicken breasts. Their findings showed that some fraction of $\mathrm{Ag}$ had migrated into the chicken meat, and higher migration rates were observed for $\mathrm{Cu}$. However, in both experiments the migrated levels did not exceed the human toxicity threshold values.

Besides $\mathrm{Ag}$ and $\mathrm{Cu}$, a number of studies have focused on carbon nanotubes embedded in composite materials as they are used in a variety of consumer products, such as tennis rackets, bicycle frames, and automobile bumpers (Klaine et al., 2008; Koehler et al., 2008). Nanocomposites consist of nanofillers embedded in a matrix of varying chemical composition, as for example cements, plastic polymers or polymer coatings (Hirth et al., 2013). The use of CNT in composite materials creates a more durable product 
that can withstand physical and chemical stress, which is why the release of CNT may occur over a much longer period of time in comparison to other ENM containing products (Farre et al., 2009).

Experimental studies have been performed to investigate the possible CNT release from cement, epoxy (Hirth et al., 2013) and thermoplastic polyurethane (TPU) (Wohlleben et al., 2013), simulating weathering and influence of mechanical stress on the CNT nanocomposites. The degradation scenarios for cement and epoxy did not result in significant release of free CNT from the products. However, weathering and abrasion had an effect on degrading the polymer matrices embedding the CNT, thus exposing a network of CNT (Hirth et al., 2013). The authors concluded that the materials can be considered safe for professional and consumer use. Similar conclusion was reached also by the study with TPU weathering and abrasion, where even the combinations of worst case scenarios for weathering and high-shear wear could result in free CNT release in amounts as little as $\mathrm{mg} / \mathrm{m}^{2} /$ year (Wohlleben et al., 2013).

\section{AC 4: Stone, plaster, cement, glass and ceramic articles}

$\mathrm{TiO}_{2}$ is also used in cement and pavement because of the self-cleaning effect that $\mathrm{TiO}_{2}$ provides. The photocatalytic activity of $\mathrm{TiO}_{2}$ helps degrading and trapping organic and inorganic particles in the air, thus removing harmful air pollutants as nitrogen oxides and volatile organic compounds (Zorita et al., 2013). Two studies (only abstracts available) have investigated the release of $\mathrm{TiO}_{2}$ from pavements (Zorita et al., 2013) and cements (Bossa et al., 2013). The simulation of weathering and abrasion of pavements for 12 weeks showed that $\mathrm{TiO}_{2}$ can be released from such materials (Zorita et al., 2013), but the information was not provided regarding the amount and characteristics of particles released. Another study investigated the release of Ti from cement samples with three different porosities, having the experimental setup of immersing the samples in ultrapure water for 7 days and then analyzing the particles released. The results indicated that release increased over time and $\mathrm{TiO}_{2}$ was emitted in particulate fractions. From the results obtained, authors hypothesized that the release of $\mathrm{TiO}_{2}$ is controlled by porosity and pore size (Bossa et al., 2013). 


\section{Consumer exposure assessment according to REACH}

Our review showed that a fair amount of studies have been performed investigating the release of nanomaterials from various consumer products. However, the question remains open whether the studies and the information provided therein can be used to complete consumer exposure assessment under the current European chemicals legislation, REACH. Under REACH, consumer products and articles are defined as substances on their own or in mixtures used by consumers and that can be purchased from retail outlets by members of the general public (ECHA, 2012).

A number of guidance documents have been developed by the European Chemical Agency (ECHA) in order to support the implementation of REACH. More specifically, consumer exposure estimation (Chapter R.15) provides a step-wise and iterative procedure for the estimation of consumer exposure to substances on their own, in mixtures or in articles. It includes guidance on:

1. Workflow for consumer exposure assessment;

2. General considerations related to assessment of consumer exposure;

3. Calculation of consumer exposure at Tier 1 level;

4. Tools for supporting exposure scenario building at Tier 1 level;

5. Higher tier models and measured data (ECHA, 2012).

Consumer exposure estimation is often difficult as it requires knowledge of the nature of the products used and of the circumstances of their intended and reasonably foreseeable use, as well as the amount of substances in consumer products or articles used per event and the frequency and duration of the event. Furthermore, release and subsequent exposure also takes place from articles or reacted/dried mixtures, which again can and is influenced by water or saliva contact, skin contact, elevated temperature, mechanical abrasion or by slow emission from the article matrix over service life. Very often assumptions have to be made and estimation has to be based on default values (ECHA, 2012). When it comes to consumers, means of controlling exposure are very limited and cannot normally be monitored, or enforced 
beyond the point of sale of the products as noted by ECHA (2012). This means that although consumer exposure estimation should normally address the intended uses of the products that contain the substances under investigation, an estimation of other reasonably foreseeable uses should be made as well since consumers may not accurately follow instructions for use of products. It can furthermore not be assumed that consumers will use Personal Protective Equipment (PPE) even if the use of PPE is recommended by the manufacturer and provided with the product (e.g., gloves with a hair dye) (ECHA, 2012).

In this review, we have used actual measured data reported in the literature, rather than assumptions on potential release from various products, to perform the consumer exposure calculations at Tier 1 level (step 3 in R.15 guidance, see above). The algorithms for calculating the inhalation, dermal and oral exposure are described in Table 1, along with explanations of when they are applicable and what kind of information they require.

\section{Estimation of inhalation exposure}

Consumer exposure to substances via inhalation can occur in a number of ways such as, for instance, many consumer products claiming to use nanomaterials are used as sprays in the form of aerosols (The Nanodatabase, 2015). Exposure by inhalation is expressed as the external exposure concentration of the substance in the breathing zone atmosphere $\left(\mathrm{mg} / \mathrm{m}^{3}\right)$, and is normally presented as an average concentration over a reference time period (e.g. per day or per event). In regard to inhalation, ECHA's guidance on consumer exposure assessment (R.15) specifically mentions: "For measurement of exposure to nanomaterials, information in relation to number concentration (especially for fibers) and surface area concentration are also considered to be of benefit (i.e. $\mathrm{n} / \mathrm{m}^{3}$ or $\left.\mathrm{cm}^{2} / \mathrm{m}^{3}\right)^{\prime \prime}(\mathrm{ECHA}, 2012)$.

The exposure estimation model assumes that all substance is released as a gas, vapour or airborne particulate (e.g. a carrier/solvent in a cosmetic formulation, a powder detergent, dust) into a standard room either due to, for instance, direct release or to evaporation from a liquid or a solid matrix. In the 
latter case, deriving the estimation of the concentration in air would represent a worst-case situation as it assumes that the substance is directly available as a gas or vapor. It furthermore assumes that the event duration is 24 hours in the worst case and that $100 \%$ of the substance in the consumer product will be released at once into the room and there is no ventilation. The equations for exposure estimation are taking into account the amount of substance in the product, volume of the room and amount of product used (Table 1). Although it is noted in R.15 that equation R. 15-1 applies to both volatile substances and airborne particulates, R. 15 also notes that "this tool has not yet been validated for use with ENMs. And that if the output of the model is used to estimate exposure for NMs, it should preferably be supported by measured data" (ECHA, 2012).

\section{Estimation of dermal exposure}

Just as exposure via inhalation, dermal exposure can occur in a number of ways. Direct hand or body contract with the consumer product or article is one prime example, but splashes on the skin and deposition on exposed skin of particles or aerosols from an airborne substance or from skin contact with residues of the substance after product use should also be considered (ECHA, 2012).

Dermal exposure is an estimate of the amount of substance contacting the exposed surfaces of the skin and is expressed in terms of the amount of substance per unit surface area of the skin exposed $\left(\mathrm{mg} / \mathrm{cm}^{2}\right)$ or as external dose ( $\mathrm{mg} / \mathrm{kg}_{\text {body weight }} /$ day) (ECHA, 2012). When it comes to estimating dermal exposure, R.15 offers two options depending on whether 1 ) the substance is contained in a mixture (e.g. direct application of the product (sunscreen), hands are put into a solution containing the substance under evaluation, or splashes occur (painting) or 2) substance migrating from an article (e.g. residual dyes in clothing are in contact with skin and migrate from the clothing). There are different algorithms available for the aforementioned exposure scenarios (Table 1 ).

\section{Estimation of oral exposure}

Oral exposure stemming from consumer products can occur from the use of household products or as a 
consequence of migration due to sucking, chewing or licking of toys, children's books or textiles. Uptake of dust and soil by children is a specific example that should also be considered if the loading of soil is related to the use and release of substances from consumer products or articles e.g. textiles.

Oral exposure is normally presented as an average daily external amount of substance ingested per kg body weight $\left(\mathrm{mg} / \mathrm{kg}_{\text {body weight }} / \mathrm{day}\right)$ and two options are available when it comes to estimating oral exposure depending on whether 1 ) the substance in a product is unintentionally swallowed during normal use, or 2 ) the substance is migrating from an article e.g. a pen, cutlery or textile (Table 1 ).

\section{Tier 1 tools that can assist exposure assessment}

A number of Tier 1 and Higher Tier models can be used to estimate consumer products. Tier 1 tools, such as ECETOC TRA, and Higher Tier tools, such as ConsExpo, require information on very few parameters and are based on a number of algorithms, but the basic principle is very similar to ECHA R.15 guidelines. They apply conservative default values and worst-case assumptions for simple screening purposes that can be changed by the assessor where relevant. For instance, as a worst-case scenario, the release of substances is assumed to be instantaneous and it is assumed that there is no removal.

\section{ECETOC TRA}

ECETOC TRA uses established exposure prediction models known as EASE (Estimation and Assessment of Substance Exposure) exposure model version 2.0 to model inhalation and dermal worker exposures and can be downloaded from http://www.ecetoc.org/tra. EASE was originally developed by the UK Health and Safety Executive (Cherrie, 2003) but has since then been modified by industry experts so that it includes considerations of the common practices in the workplace (e.g. selection of Process Categories (PROC) and Risk Management Measures (RMM)) to enable a wider user community to make a rapid and conservative assessment, which can be used as a first tier to demonstrate low risk for a specific scenario of use, eliminates the subsequent need to collect and use measured exposure data for another assessment of the 
same scenario. The outcome of using ECETOC TRA is a description of the type and basic conditions of use which can then be translated into a calculated exposure using an exposure model.

Independent of exposure route, a product/article category and subcategory has to be selected and the default values associated with subcategories e.g. amount of product used per application and exposure time were obtained from the RIVM (The National Institute for Public Health and the Environment, Netherlands) fact sheets for specific products, in order to build consistency with ConsExpo (described in the next section). The user of ECETOC TRA may use the given defaults (presented in the defaults table of the tool) for the fraction of substance (product ingredient) in consumer product or article, or the users can choose to use their own values by overwriting the default values suggested by the tool (ECETOC, 2009; ECHA, 2014).

For inhalation, ECETOC TRA calculates the inhalation exposure as either the concentration in room air $\left(\mathrm{mg} / \mathrm{m}^{3}\right)$ over a day, resulting from one or more events of product/article application or as the dose (amount per kg bodyweight) inhaled over the duration of the event (20 min to $8 \mathrm{~h}$, depending on the product category).

When it to comes to calculating the dermal exposure of consumers, the user can select two parameters: the fraction of substance in the product (i.e. product ingredient) or article and the skin contact area (if defaults are not suitable for the assessment) after which, ECETOC TRA uses algorithms for dermal exposure assessment (Table S2b in Supporting Information).

For some article categories exposure related mouthing is calculated in the ECETOC TRA and in such cases, the volume of product swallowed is calculated based on the article area in contact with the mouth CA, which is set as a default value of $10 \mathrm{~cm}^{2}$ and the thickness of article layer TL assumed to be in contact during mouthing, which is set as a default value of 0.01 or $0.001 \mathrm{~cm}$ and it is assumed that $100 \%$ of 
substance present in the contact layer is transferred and available for ingestion (ECETOC, 2009; ECHA, 2014).

\section{ConsExpo}

ConsExpo (version 4.1) is a higher Tier tool recommended by ECHA (2012) for expert consumer exposure assessments. ConsExpo is based on equations published by Delmaar et al. (2005) and the computer program can be downloaded from www.consexpo.nl).

Based on basic information about the product, compound and exposed person, exposure route and use scenario of the product, ConsExpo uses different exposure and uptake models to estimate inhalation, dermal or oral exposure to compounds in consumer products. ConsExpo can be used to estimate exposure for different scenarios for which measured data is insufficient or lacking. More detailed and complex models can be used if more data is available and the more refined exposure assessment can be completed. As specific data needed for the more advanced models is often hard to come by, ConsExpo draws on a database of default products for which exposure scenarios have been defined and default values for their model input parameters, which have been compiled from literature (Delmaar et al., 2005).

Essentially the algorithms under ConsExpo calculations (Table S2c in Supporting Information) are very similar to those from R.15 guidance document. However, in contrast to the equations in R.15 and the equations used in ECETOC TRA, ConsExpo enables parameters to be specified as distributions, which is handy when it comes to parameters such as weight. ConsExpo used these distributions to perform a distributed (Monte Carlo) calculation of the endpoint of choice and can draw a set of random numbers from uniform, normal, lognormal, and/or triangular distributions for the distributed parameters (ECHA, 2012). Sensitivity analysis is also possible via ConsExpo to analyse how sensitive exposure and uptake estimates are to variations in the value of a single parameter (Delmaar et al., 2005).

For inhalation of vapours that evaporates from a surface into the air (from a painted wall), ConsExpo calculates the air concentration of a compound at time $t$ for the instantaneous release or constant release 
(see Table S2c in Supporting Information).

As with inhalation exposure, ConsExpo enables the calculation of dermal exposure in situations where all of a compound in the product is directly applied to the skin instantaneously as well as situations in which a compound is loaded onto the skin during a certain time, with a constant rate. ConsExpo also allows for dermal exposure assessment of situations in which a surface (table top, floor) is treated with a product and dermal exposure arises from contact with the treated surface as well as the migration of a compound from a material to the skin when dermal contact with the material occurs and diffusion, i.e. situations, in which a product is applied to the skin and the compound subsequently diffuses through the product to the skin (Table S2c in Supporting Information).

For oral exposure, ConsExpo has two features, namely direct intake and constant rate oral intake as well as migration oral exposure and migration from packaging material (see TableS2c in Supporting Information). ConsExpo also includes inhalation via sprays, but these are not considered here since we focus on solid nanoproducts and nanocomposites. Same goes for the Inhalation fractional uptake model and the dermal and oral uptake models (Delmaar et al., 2005; ECHA, 2012).

\section{Applying REACH algorithms to ENM release literature}

ECHA's technical guidance document, Chapter R.15 provides a number of equations, Tier 1 and Higher Tier tools for estimating inhalation, dermal and oral exposure from consumer products. Experimental studies reviewed on the release of nanoparticles from solid consumer products and nanocomposites provide a lot of valuable information, but many of them do not report their results in a format that directly allows using consumer exposure equations laid down in REACH and ECHA's technical guidance document, Chapter R.15 (ECHA, 2012). 
Table S1 in Supporting Information provides an overview of all the studies addressing release from ENMcontaining solid articles, and some of those provide relevant data that can subsequently be used to derive consumer exposure estimates by using either the equations listed in R.15 (ECHA, 2012) and/or ECETOC TRA (ECETOC, 2009) and ConsExpo (Delmaar et al., 2005) (Table S3a, S3b, S3c, S3d in Supporting Information).

Out of the 76 studies identified in the literature review, 33 entailed information that could be used to derive consumer exposure estimates for one or more exposure routes. For consumer exposure estimation, one of the key parameters that we were looking for in the publications was the concentration of the chemical in the medium that consumer might be exposed to, meaning that when it comes to the term "concentration of substance in product" (C for R.15 and ConsExpo, and PI for ECETOC TRA), we were looking for a number that represents the amount of substance migrated into the washing liquid (if it is for dermal exposure) or food simulants (for oral exposure) or into air (for inhalation exposure), rather than using the concentration of substance in the actual product and assuming instantaneous $100 \%$ release.

The generation of exposure scenario(s) is a key aspect for consumer exposure assessment under REACH, the registrant has a lot of flexibility when it comes to building an exposure scenario. Very seldom do authors of the scientific articles reviewed in this paper on ENM release generate exposure scenarios and hence we had to make numerous assumptions in order to apply the equations in R.15, ECETOC TRA and ConsExpo. For instance, we had to make assumptions about the weight of T-shirts, gloves, underwear, sippy rings, dermal wipes, and many more products (see Table S3b, S3c, S3d in Supporting Information). We based our assumptions about product weight on the information from online retailers (Table S4 in Supporting Information).

Another challenge relates to the manner in which the substance release from consumer products is reported in the scientific literature. A number of studies report the release in a metric that cannot be converted to the metric used in R.15, ECETOC TRA and ConsExpo i.e. g/g. For instance, they might report 
the particle number released per volume from a given paint or coating (Le Bihan et al., 2013; Vorbau et al., 2009a; Guiot et al., 2009; Gomez et al., 2014; Koponen et al., 2011; Sachse et al., 2012b; Sachse et al., 2013; Hsu and Chein, 2007), but not the mass of the material released $\left(C_{\text {inh }}\left[\mathrm{mg} / \mathrm{m}^{3}\right]\right)$ that one would need in order to use the equations for inhalation exposure assessment. When data is lacking, the R.15 guidance document suggests using the worst case scenario, assuming that $100 \%$ of the substance is released into air. This can be a valid assumption for volatile chemicals, but even though it is highly unlikely for the nanoparticles that are embedded into a solid matrix, we still used the amount of chemical in a paint or coating and assumed that all of it would be released into air through sanding, abrasion or other methods. We identified only one study which provided information on actual mass release into air (Mazzuckelli et al., 2007).

The results from consumer exposure assessment calculations are illustrated in Figure 4, presenting the possible inhalatory, dermal or oral dose in $\mathrm{mg}$ of substance per $\mathrm{kg}$ body weight per day $\left(\mathrm{mg} / \mathrm{kg}_{\mathrm{bw}} / \mathrm{d}\right)$. The results are grouped according to the product groups and ranked by the extent of potential exposure. The results for concentration of substance in the air of the room $\left(\mathrm{mg} / \mathrm{m}^{3}\right)$ had the same outcome for all three models (R.15, ConsExpo, ECETOC TRA), though only R.15 provides equation for calculating the inhalatory dose of substance per day and per body weight. For these reasons the results presented are only for the outcome for inhalatory dose (Figure 4A). The input data and assumptions are described in Table S3a in Supporting Information.

For dermal exposure we considered two relevant scenarios - a) washing of nanoparticle-containing textiles which is leading to dermal exposure to wash-water (referred to as Dermal A in R.15) (Figure 4B), and b) having direct contact to the product from which the substance can migrate into e.g. sweat (referred to as Dermal B in R.15) (Figure 4C).

For Dermal A scenario we considered studies that provided experimental data on release from different textiles into water, or water with detergent. We assumed that the exposed area would be only the skin of 
both sides of both hands that could be affected during washing. If not stated in the publication, we assumed the fabric weight of $200 \mathrm{~g}$ (a weight of a T-shirt, see Table S4 in Supporting Information). The volume of the washwater was assumed to be $10 \mathrm{~L}$ and only one event per day was considered.

For Dermal B scenario the key input for the model was the amount of substance in the product and the fraction that could migrate from the article to the skin. If not provided by the publication, we found the weight of different products from online retailers, and made assumptions on how long time the article would be in contact with skin.

Oral exposure estimation included mainly migration from food containers into food simulants, and one study on release from ceramic water filters. For all those products, we did not assume the ingestion of the whole article (i.e. solid nanocomposite), but used the values for quantity of substance that has migrated into media relevant for ingestion (e.g. water, food simulants, chicken meat) (see Table S3d in Supporting Information). The results from exposure assessment are shown below in Figure 4D.

\section{Discussion}

\section{Current Knowledge Gaps and Research Needs}

The experimental case studies described above show that there is some information available on release rates of ENM from consumer products. However, the number of studies is very small and therefore there is a great need to conduct and publish more studies to improve the understanding of rates and forms of ENM release. So far the research has been focused on very small set of possible products (such as paints, textiles, coatings), and the conclusions drawn from the obtained data cannot be extrapolated to other consumer product groups. Also there are very few nanomaterial types tested (mainly $\mathrm{Ag}, \mathrm{TiO}_{2}, \mathrm{CNT}$ ), even though there are many others used in various consumer products (e.g. $\mathrm{ZnO}, \mathrm{Au}, \mathrm{SiO}_{2}$ ) (The Nanodatabase, 2015). To get a better overview of ENM release from consumer products more product groups and different ENM types have to be investigated. 
The research done so far has furthermore been attempting to illustrate ENM release rates in relatively short time frames (short relative to the real-life use of the product) and imitating only few usage scenarios that are characterizing the possible emissions. The experimental setups are often far from the real-life conditions, which makes it difficult to interpret the data in the context of environmental and consumer risk of exposure. For example, washing of textiles without detergent cannot provide characterization of real-life emissions of ENM. As it is very time consuming and expensive to attempt to imitate the whole use-phase of the life cycle of a certain product, it is necessary to find a method that would be representative enough for describing the ENM release rates over a longer period of time.

Even though it is well recognized that the release of ENMs from consumer products is a relevant factor for risk assessment, there is a distinct lack of analytical information available regarding the potential release (Gottschalk and Nowack, 2011). Majority of the publications focuses on mass-based release rather than particle-based. A number of studies indicate whether or not there were any actual nanoparticles released, but with the current analytical techniques available, it is difficult to quantify the amount of particles released. The particle release forms and kinetics are product-specific and are highly dependent on the manufacturing process (Nowack et al., 2012), which makes it difficult to generalize the ENM release from different consumer product groups. Also the experimental setups applied for determining the release rates are very different. For example, the ENM release from fabrics has been investigated using ultrapure water (Benn and Westerhoff, 2008; Pasricha et al., 2012), tap water (Benn et al., 2010), washing solutions (Windler et al., 2012) or artificial sweat (Kulthong et al., 2010; von Goetz et al., 2013a; Yan et al., 2012), each giving different outcome. Therefore there are a lot of variables that have to be taken into account when interpreting the results, such as exposure temperature, duration of the experiment, $\mathrm{pH}$, etc.

Currently the analytical methods for characterization of ENM are very limited and mostly designed for detecting nanomaterials in pristine conditions. It is way more complicated to acquire data regarding the behavior of ENM in complex media at realistic concentrations and conditions (Klaine et al., 2012). The 
behavior of ENM in the matrix and in the environment will be affected by a wide range of factors, such as particle number and mass concentration, surface area, charge, chemistry, reactivity, size distribution, state of aggregation, elemental composition, as well as structure and shape (Chau et al., 2007). Therefore the analysis of ENM is different from traditional chemical analysis because both chemical and physical forms must be considered. ENM exist in colloidal systems with wide range of different properties, which is why it is equally important for detection and analysis to address not only chemical but also physical form (Hassellöv et al., 2008).

Ideally, analytical methods should provide information on: (i) whether the certain substance is in the sample (identity); (ii) how much of the substance is found in the sample (mass or number of particles) and (iii) in what physical form and size the particles are present in the sample. A wide range of analytical tools is available for characterizing systems containing ENM to address the aforementioned questions, but they have a lot of limitations when it comes to analyzing samples containing nanomaterials (von der Kammer et al., 2012).

\section{Exposure Estimations and Challenges when Using ECHA's R.15 Guidance for ENMs}

The results we obtained by compiling the studies in the scientific literature and extracting data for consumer exposure estimation using ECHA's REACH guidelines raised more questions than answers. When it comes to nanomaterials, it is very unclear what would constitute a reasonable exposure assessment, i.e. is it particle number or size-based assessment, or mass based approach.

Studies we found relevant for inhalation exposure mostly reported data as particle number release per volume of air, which does not provide any information on particle composition. Therefore, for most of the studies we assumed the worst case scenario- that all of the nanoparticles incorporated in the matrix of the product would be released into air instantaneously. We found that exposures could go as high as 40 $\mathrm{mg} / \mathrm{kg}_{\mathrm{bw}} / \mathrm{day}$ (Gomez et al., 2014) (see Figure 4A), however, the exposure was magnitudes lower for the only study (Mazzuckelli et al., 2007) that we found which reported data on mass concentration of actual 
substance in air. It is especially challenging to detect the mass concentration of nanoparticles in air, as they vary in size and are often associated to the matrix of the product. Several studies have attempted to use TEM or SEM with EDS (Shandilya et al., 2014; Vorbau et al., 2009b; Bello et al., 2009; Golanski et al., 2012; Schlagenhauf et al., 2012) to find the ENM in the released particles during sanding or abrasion, but this does not provide quantitative information on ENM release.

The results for dermal exposure assessment for nanomaterial-containing articles (Figure 4B, 4C) showed that the amounts consumers are exposed to are negligible. When it comes to different types of fabrics, the highest release, and therefore exposure potential, was for fabrics prepared in laboratory rather than commercially available textiles. Other than that, there were no clear patterns or possible rankings according to different product types. The oral exposure calculations did not show any clear pattern according to the product type either, however, the highest possible exposure was calculated for $\mathrm{Ag}$ leaching into water from ceramic water filters (Figure 4D) (Ren and Smith, 2013).

The comparison, grouping and ranking for the exposure potential for different products is difficult, as the studies are rarely addressing the same products, and they are having different experimental setups and different ways to measure the release and present the data. Figure 4 illustrates that it is difficult to generalize exposure to the same ENM within the product groups, as even within the same product group the exposure dose can vary from $\mathrm{ng} / \mathrm{kg}_{\mathrm{bw}} / \mathrm{d}$ to $\mathrm{mg} / \mathrm{kg}_{\mathrm{bw}} / \mathrm{d}$, as e.g. for fabrics, textiles and apparel (Figure 4B, 4C). If we could include particle size and number as a variable in the model, it could provide much more relevant information, such as e.g. the likelihood of particles to penetrate skin if the product use can result in dermal exposure.

Furthermore, more than half of the studies investigated in this review were not suitable for consumer exposure estimation calculations according to ECHA R.15 guidance. This underlines that fact that we do not only we need more studies that are suitable for exposure estimation, but that we also need to make sure that key data such as weight of the product, concentration of substance in the product, and released 
amount, is always reported in future studies, so that the reported results are not only scientifically relevant, but also regulatory relevant and can be used in relation to consumer exposure assessment.

Finally, in this review we have successfully applied ECHA models, as well as ConsExpo and ECETOC TRA by using information from some of the studies available in the open literature in order to derive a mass based consumer exposure assessment for a given scenario. But the question is whether the ECHA models, etc. should indeed be used given all the limitations that we have noted above and given the fact that none of these models were originally development of nanoparticles. Limited research has so far been done in this regard. Cushen et al. (2014b) developed their own migration models based on mathematical equations for polyolefins and not to non-amorphous polymers and the Williams- Landel- Ferry equation for timetemperature superposition and found that their models accurately predicted the nanosilver levels in observed in laboratory migration tests, whereas the model was less accurate for nanocopper.

Von Goetz et al. (2013a) developed a model for consumer exposure to substances in textiles that describes migration of a nonvolatile substance from textile fabric, i.e., the amount of $\mathrm{Ag}$ or $\mathrm{TiO}_{2}$ depositing on the skin surface during a single use. Von Goetz et al. (2013a) used the model to calculated the external dermal exposure to $\mathrm{Ag}$ and $\mathrm{TiO} 2$ and modelled the data separately for dissolved and particulate material.

$$
E=m_{\text {textile }} a_{\text {subs }} r_{\text {sweat }} t_{\text {expo }} A_{\text {expo }} f_{\text {contact }} m_{\text {bw }}^{-1}
$$

"where $E$ is the external exposure per use [ $\mu \mathrm{g}$ substance per kg body weight], $m_{\text {textile }}$ is the total weight of textile $[\mathrm{g}], \mathrm{a}_{\text {subs }}$ is the released amount of substance from fabric into sweat per gram fabric and $\mathrm{mL}$ sweat $[\mu \mathrm{g} / \mathrm{g} / \mathrm{mL}], r_{\text {sweat }}$ is the released volume of sweat per time and body surface $\left[\mathrm{mL} / \mathrm{min} / \mathrm{m}^{2}\right]$, $t_{\text {expo }}$ is the exposure time $[\mathrm{min}], A_{\text {expo }}$ is the body surface area covered by a piece of clothing $\left[\mathrm{m}^{2}\right], \mathrm{f}_{\text {contact }}$ is the fraction of textile in close contact with sweat and skin, and $m_{b w}$ is the body weight of the consumer [kg body weight]." 
The work by Cuhsen et al. (2014b) and Von Goetz et al. (2013a) is helpful when it comes to deriving mass based consumer exposure assessment, but the question is whether this is enough to take the unique properties of nanoparticles into consideration when it comes to exposure assessment. For some nanomaterials (e.g. zinc oxide) the argument could be made that observed toxicity is due to the dissolved metals (ions), and that a worst case scenario could be to assume that all release occurs as dissolved metals. It, however, has to be noted that some researchers have observed "nanospecific"-effects in, for instance, ecotoxicological studies (Luoma et al., 2014). Research and evidence of toxicological studies have consistently shown that particle number and/or the specific surface areas might be a better metric to describe the toxic potential of a given nanoparticles and one has to wonder whether this might also be the case of exposure assessment of nanoparticles.

\section{Conclusions}

The experimental case studies reported in the literature provide solid evidence for the release of ENM from various ENM-containing consumer products. There are limitations regarding the analytical techniques available to quantify and characterize the particles released. So far it has been shown that the particles that are released are usually very different from the ENM that have been embedded in the product, and it is more likely that ENM is still embedded in the matrix of the product rather than released as single particles.

Most studies investigating the release from ENM-containing consumer products do not reflect the realistic conditions and therefore are not able to illustrate the actual emissions and characterize the released particles. For example, the analysis of particle release from textiles is not very representative of the realworld situation for e.g. washing of textiles if the experiment is conducted in distilled water (Benn and Westerhoff, 2008; Pasricha et al., 2012) or tap water (Benn et al., 2010) and the washing process is not simulated. Also, mechanical stress on textiles during washing and wearing has to be considered, as well as the frequency of usage. The studies using washing machines and detergents (Windler et al., 2012; Impellitteri et al., 2009; Geranio et al., 2009) are more representative, but still they are only covering a 
small part of the life cycle of selected product. Future research needs to work on finding a single examined release process that would be representative enough for processes taking place during use of the products, as well as developing more generalized methods for representing ENM release processes from different product groups at relevant environmental conditions. Focus should also be set on improving analytical methods for determining ENM alteration and transformation when being used. This kind of data would help estimating ENM release rates from particular products, which can further be used for e.g. modeling exposure concentrations and risk assessment.

\section{Acknowledgment}

This project has received funding from the European Union's Seventh Framework Programme [FP7/20072013] under EC-GA No. 604305 'SUN'.

\section{Declaration of interest}

The authors declare no conflicts of interest.

\section{References}

Al-Kattan A, Wichser A, Vonbank R, Brunner S, Ulrich A, Zuin S, Nowack B. 2013. Release of TiO2 from paints containing pigment-TiO2 or nano-TiO2 by weathering. Environmental Science: Processes \& Impacts 15:2186-2193.

Al-Kattan A, Wichser A, Vonbank R, Brunner S, Ulrich A, Zuin S, Arroyo Y, Golanski L, Nowack B. 2014. Characterization of materials released into water from paint containing nano-SiO2. Chemosphere 119:1314-1321. 
Artiaga G, Ramos K, Ramos L, Cámara C, Gómez-Gómez M. 2014. Migration and characterisation of nanosilver from food containers by AF4-ICP-MS. Food Chem. 166:76-85.

Bello D, Wardle BL, Yamamoto N, Guzman deVilloria R, Garcia EJ, Hart AJ, Ahn K, Ellenbecker MJ, Hallock M. 2009. Exposure to nanoscale particles and fibers during machining of hybrid advanced composites containing carbon nanotubes. Journal of Nanoparticle Research 11:231-249.

Benn TM, Westerhoff P. 2008. Nanoparticle silver released into water from commercially available sock fabrics. Environ Sci Technol Environmental science \& technology 42:4133-4139.

Benn T, Cavanagh B, Hristovski K, Posner JD, Westerhoff P. 2010. The Release of Nanosilver from Consumer Products Used in the Home. J Environ Qual 39:1875-1882.

Bossa N, Rose J, Chaurand P, Aguerre-Chariol O. 2013. Release of TiO2 nanoparticles from cement during their life cycle: step of use. Abstract from 8th International Conference on the Environmental Effects of Nanoparticles and Nanomaterials.

Chau CF, Wu SH, Yen GC. 2007. The development of regulations for food nanotechnology. Trends Food Sci Technol 18:269-280.

Cherrie J. 2003. Evaluation of Further Development of the EASE Model 2.0: HSE Books.

Cushen M, Kerry J, Morris M, Cruz-Romero M, Cummins E. 2013. Migration and exposure assessment of silver from a PVC nanocomposite. Food Chem 139:389-397.

Cushen M, Kerry J, Morris M, Cruz-Romero M, Cummins E. 2014a. Silver migration from nanosilver and commercially available zeolite filler polyethylene composites to food simulants. Food Additives \& Contaminants: Part A 31.6:1132-1140. 
Cushen M, Kerry J, Morris M, Cruz-Romero M, Cummins E. 2014b. Evaluation and simulation of silver and copper nanoparticle migration from polyethylene nanocomposites to food and an associated exposure assessment. J Agric Food Chem 62:1403-1411.

Delmaar J, Park M, Van Engelen J. 2005. ConsExpo 4.0 - Consumer exposure and uptake models - Program manual, http://rivm.openrepository.com/rivm/bitstream/10029/7307/1/320104004.pdf.

ECETOC. 2014. Technical Report No. 124 : Addendum to TR114 : Technical Basis for the TRA v3.1. European Centre for Ecotoxicology and Toxicology of Chemicals, Brussels, Belgium.

ECETOC. 2012. Technical Report No. 114 : ECETOC TRA version 3: Background and Rationale for the Improvements. European Centre for Ecotoxicology and Toxicology of Chemicals, Brussels, Belgium.

ECETOC. 2009. Technical Report No. 107: Addendum to ECETOC Targeted Risk Assessment Technical Report No. 93. European Centre for Ecotoxicology and Toxicology of Chemicals, Brussels, Belgium.

ECETOC. 2004. Technical Report No. 93: Targeted risk assessment. European Centre for Ecotoxicology and Toxicology of Chemicals, Brussels, Belgium.

ECHA. 2014. Guidance on information requirements and chemical safety assessment. http://echa.europa.eu/guidance-documents/guidance-on-information-requirements-andchemical-safety-assessment.

ECHA. 2012. Guidance on information requirements and chemical safety assessment, Chapter R. 15: Consumer exposure estimation. http://echa.europa.eu/documents/10162/13632/information_requirements_r15_en.pdf.

Echegoyen Y, Nerín C. 2013. Nanoparticle release from nano-silver antimicrobial food containers. Food and Chemical Toxicology 62:16-22. 
European Parliament and the Council of the European Union. 2008. No. 1272/2008 of the European Parliament and of the Council, on Classification, Labeling and Packaging of Substances and Mixtures, Amending and Repealing Directives 67/548/EEC and 1999/45/EC, and Amending Regulation (EC) No. 1907/2006. Official Journal of the European Union 353.

European Parliament and the Council of the European Union. 2006. Regulation (EC) no. 1907/2006 of the European Parliament and of the Council of 18 December 2006 concerning the registration, evaluation, authorization and restriction of chemicals (REACH), establishing a European Chemicals Agency, amending Directive 1999/45/EC and repealing Council Regulation (EEC) no. 793/93 and Commission Regulation (EC) no. 1488/94, as well as Council Directive 76/769/EEC and commission Directives 91/155/EEC, 93/67/EEC, 93/105/CE and 2000/21/EC. Official Journal of the European Union 396.

Farre M, Gajda-Schrantz K, Kantiani L, Barcelo D. 2009. Ecotoxicity and analysis of nanomaterials in the aquatic environment. Anal Bioanal Chem 393:81-95.

Froggett SJ, Clancy SF, Boverhof DR, Canady RA. 2014. A review and perspective of existing research on the release of nanomaterials from solid nanocomposites. Part Fibre Toxicol 11:17-8977-11-17.

Ganzleben C, Hansen SF. 2012. Environmental Exposure to Nanomaterials - Data Scoping Study: Final Report. Milieu Ltd., Brussels, Belgium. Environmental Exposure to Nanomaterials-Data Scoping Study: Final Report.

Geranio L, Heuberger M, Nowack B. 2009. The Behavior of Silver Nanotextiles during Washing. Environ Sci Technol 43:8113-8118.

Göhler D, Nogowski A, Fiala P, Stintz M. 2013. Nanoparticle release from nanocomposites due to mechanical treatment at two stages of the life-cycle. Journal of Physics: Conference Series 429 No. 1. IOP Publishing. 
Gohler D, Stintz M, Hillemann L, Vorbau M. 2010. Characterization of nanoparticle release from surface coatings by the simulation of a sanding process. Ann Occup Hyg 54:615-624.

Golanski L, Guiot A, Pras M, Malarde M, Tardif F. 2012. Release-ability of nano fillers from different nanomaterials (toward the acceptability of nanoproduct). Journal of Nanoparticle Research 14:1-9.

Gomez V, Levin M, Saber AT, Irusta S, Dal Maso M, Hanoi R, Santamaria J, Jensen KA, Wallin H, Koponen IK. 2014. Comparison of Dust Release from Epoxy and Paint Nanocomposites and Conventional Products during Sanding and Sawing. Ann Occup Hyg. Meu046.

Gottschalk F, Nowack B. 2011. The release of engineered nanomaterials to the environment. J Environ Monit 13:1145-1155.

Guiot A, Golanski L, Tardif F. 2009. Measurement of nanoparticle removal by abrasion. Journal of Physics: Conference Series 170. No. 1. IOP Publishing.

Handy RD, Kammer Fvd, Lead JR, Hassellov M, Owen R, Crane M. 2008. The ecotoxicology and chemistry of manufactured nanoparticles. Ecotoxicology 17:287-314.

Hansen SF, Maynard A, Baun A, Tickner JA, Bowman DM. 2013. Nanotechnology-early lessons from early warnings. Late lessons from early warnings: science, precaution, innovation. EEA Report :562-591.

Hassellöv M, Readman JW, Ranville JF, Tiede K. 2008. Nanoparticle analysis and characterization methodologies in environmental risk assessment of engineered nanoparticles. Ecotoxicology 17:344-361.

Hauri JF, Niece BK. 2011. Leaching of Silver from Silver-Impregnated Food Storage Containers. J Chem Educ 88:1407-1409. 
Hedberg J, Skoglund S, Karlsson M, Wold S, Odenvall WI, Hedberg YS. 2014. Sequential studies of silver released from silver nanoparticles in aqueous media simulating sweat, laundry detergent solutions and surface water. Environ Sci Technol. 48(13):7314-7322.

Hirth S, Cena L, Cox G, Tomovic Å, Peters T, Wohlleben W. 2013. Scenarios and methods that induce protruding or released CNTs after degradation of nanocomposite materials. J Nanopart Res 15:1-15.

Hsu L, Chein H. 2007. Evaluation of nanoparticle emission for TiO2 nanopowder coating materials. J Nanopart Res 9:157-163.

Huang Y, Chen S, Bing X, Gao C, Wang T, Yuan B. 2011. Nanosilver migrated into food-simulating solutions from commercially available food fresh containers. Packaging technology \& science 24:291-297.

Impellitteri CA, Tolaymat TM, Scheckel KG. 2009. The Speciation of Silver Nanoparticles in Antimicrobial Fabric Before and After Exposure to a Hypochlorite/Detergent Solution. J Environ Qual 38:1528-1530.

Kaegi R, Ulrich A, Sinnet B, Vonbank R, Wichser A, Zuleeg S, Simmler H, Brunner S, Vonmont H, Burkhardt M, Boller M. 2008. Synthetic TiO2 nanoparticle emission from exterior facades into the aquatic environment. Environmental Pollution 156:233-239.

Kaegi R, Sinnet B, Zuleeg S, Hagendorfer H, Mueller E, Vonbank R, Boller M, Burkhardt M. 2010. Release of silver nanoparticles from outdoor facades. Environmental Pollution 158:2900-2905.

Klaine SJ, Alvarez PJJ, Batley GE, Fernandes TF, Handy RD, Lyon DY, Mahendra S, McLaughlin MJ, Lead JR. 2008. Nanomaterials in the environment: Behavior, fate, bioavailability, and effects. Environmental Toxicology and Chemistry 27:1825-1851. 
Klaine SJ, Koelmans AA, Horne N, Carley S, Handy RD, Kapustka L, Nowack B, von der Kammer F. 2012. Paradigms to assess the environmental impact of manufactured nanomaterials. Environmental Toxicology and Chemistry 31:3-14.

Koehler AR, Som C, Helland A, Gottschalk F. 2008. Studying the potential release of carbon nanotubes throughout the application life cycle. J Clean Prod 16:927-937.

Koponen I, Jensen K, Schneider T. 2009. Sanding dust from nanoparticle-containing paints: physical characterization. Journal of Physics: Conference Series 151. No. 1. IOP Publishing.

Koponen IK, Jensen KA, Schneider T. 2011. Comparison of dust released from sanding conventional and nanoparticle-doped wall and wood coatings. Journal of exposure science and environmental epidemiology 21:408-418.

Kulthong K, Srisung S, Boonpavanitchakul K, Kangwansupamonkon W, Maniratanachote R. 2010.

Determination of silver nanoparticle release from antibacterial fabrics into artificial sweat. Particle and Fibre Toxicology 7:8.

Le Bihan O, Shandilya N, Gheerardyn L, Guillon O, Dore E, Morgeneyer M. 2013. Investigation of the Release of Particles from a Nanocoated Product. Advances in Nanoparticles 2:39-44.

Lin Q, Li H, Zhong H, Zhao Q, Xiao D, Wang Z. 2014. Migration of Ti from nano-TiO2-polyethylene composite packaging into food simulants. Food Additives \& Contaminants: Part A 31.7:1284-1290.

Liu J, Hurt RH. 2010. Ion Release Kinetics and Particle Persistence in Aqueous Nano-Silver Colloids. Environ Sci Technol 44:2169-2175. 
Lorenz C, Windler L, von Goetz N, Lehmann RP, Schuppler M, Hungerbuehler K, Heuberger M, Nowack B.

2012. Characterization of silver release from commercially available functional (nano)textiles. Chemosphere 89:817-824.

Luoma SN, Rainbow PS. (2008). Metal contamination in aquatic environments: science and lateral management. Cambridge University Press.

Luoma SN, Khan FR, Croteau MN. (2014). Bioavailability and bioaccumulation of metal-based engineered nanomaterials in aquatic environments: concepts and processes: chapter 5. DOI: 10.1016/B978-0-08099408-6.00005-0.

Lynch I. 2014. Compendium of projects in the European NanoSafety Cluster. Brussels: European Commission 2014 Edition.

Mazzuckelli LF, Methner MM, Birch ME, Evans DE, Ku B, Crouch K, Hoover MD. 2007. Identification and characterization of potential sources of worker exposure to carbon nanofibers during polymer composite laboratory operations. Journal of occupational and environmental hygiene 4:D125-D130.

Mitrano DM, Rimmele E, Wichser A, Erni R, Height M, Nowack B. 2014. Presence of Nanoparticles in Wash Water from Conventional Silver and Nano-Silver Textiles. ACS Nano 8(7), 7208-7219.

Nowack B. 2009. The behavior and effects of nanoparticles in the environment. Environmental Pollution 157:1063-1064.

Nowack B, Bucheli TD. 2007. Occurrence, behavior and effects of nanoparticles in the environment. Environmental Pollution 150:5-22. 
Nowack B, Ranville JF, Diamond S, Gallego-Urrea J, Metcalfe C, Rose J, Horne N, Koelmans AA, Klaine SJ. 2012. Potential scenarios for nanomaterial release and subsequent alteration in the environment. Environmental Toxicology and Chemistry 31:50-59.

Ogura I, Kotake M, Shigeta M, Uejima M, Saito K, Hashimoto N, Kishimoto A. 2013. Potential release of carbon nanotubes from their composites during grinding. Journal of Physics: Conference Series 429. No. 1. IOP Publishing.

Olabarrieta J, Zorita S, Peña I, Rioja N, Monzón O, Benguria P, Scifo L. 2012. Aging of photocatalytic coatings under a water flow: Long run performance and TiO2 nanoparticles release. Applied Catalysis B: Environmental 123:182-192.

Ostertag K, Hasing B. 2008. Identification of starting points for exposure assessment in the post-use phase of nanomaterial-containing products. J Clean Prod 16:938-948.

Pasricha A, Jangra SL, Singh N, Dilbaghi N, Sood KN, Arora K, Pasricha R. 2012. Comparative study of leaching of silver nanoparticles from fabric and effective effluent treatment. Journal of Environmental Sciences 24:852-859.

Quadros ME, Pierson IV R, Tulve NS, Willis R, Rogers K, Thomas TA, Marr LC. 2013. Release of silver from nanotechnology-based consumer products for children. Environ Sci Technol 47:8894-8901.

Raynor PC, Cebula JI, Spangenberger JS, Olson BA, Dasch JM, D’Arcy JB. 2012. Assessing potential nanoparticle release during nanocomposite shredding using direct-reading instruments. Journal of occupational and environmental hygiene 9:1-13.

Ren D, Smith JA. 2013. Retention and transport of silver nanoparticles in a ceramic porous medium used for point-of-use water treatment. Environ Sci Technol 47:3825-3832. 
Saber AT, Koponen IK, Jensen KA, Jacobsen NR, Mikkelsen L, Møller P, Loft S, Vogel U, Wallin H. 2012. Inflammatory and genotoxic effects of sanding dust generated from nanoparticle-containing paints and lacquers. Nanotoxicology 6:776-788.

Sachse S, Gendre L, Silva F, Zhu H, Leszczyńska A, Pielichowski K, Ermini V, Njuguna J. 2013. On nanoparticles release from polymer nanocomposites for applications in lightweight automotive components. Journal of Physics: Conference Series 429. No. 1. IOP Publishing.

Sachse S, Silva F, Irfan A, Zhu H, Pielichowski K, Leszczynska A, Blazquez M, Kazmina O, Kuzmenko O, Njuguna J. 2012a. Physical characteristics of nanoparticles emitted during drilling of silica based polyamide 6 nanocomposites. IOP Conference Series: Materials Science and Engineering 40. No. 1. IOP Publishing.

Sachse S, Silva F, Zhu H, Irfan A, Leszczyńska A, Pielichowski K, Ermini V, Blazquez M, Kuzmenko O, Njuguna J. 2012b. The effect of nanoclay on dust generation during drilling of PA6 nanocomposites. Journal of Nanomaterials 2012:26.

Schlagenhauf L, Chu BT, Buha J, Nüesch F, Wang J. 2012. Release of carbon nanotubes from an epoxy-based nanocomposite during an abrasion process. Environ Sci Technol 46:7366-7372.

Shandilya N, Le Bihan O, Bressot C, Morgeneyer M. 2014. Evaluation of the particle aerosolization from nTiO2 photocatalytic nanocoatings under abrasion. Journal of Nanomaterials 6.

Som C, Berges M, Chaudhry Q, Dusinska M, Fernandes TF, Olsen SI, Nowack B. 2010. The importance of life cycle concepts for the development of safe nanoproducts. Toxicology 269(2):160-169.

Stefaniak AB, Duling MG, Lawrence RB, Thomas TA, LeBouf RF, Wade EE, Abbas Virji M. 2014. Dermal exposure potential from textiles that contain silver nanoparticles. International Journal of Occupational and Environmental Health 20:220-234. 
The Nanodatabase. 2015. Available at: http://nanodb.dk. Accessed in June 2015.

The Project on Emerging Nanotechnologies (PEN). 2013. Available at: http://www.nanotechproject.org/. Accessed in June 2015.

Varner KE, Rindfusz K, Gaglione A, Viveiros E. 2010. Nano Titanium Dioxide Environmental Matters: State of the Science Literature Review. U.S. Environmental Protection Agency, Washington, DC, EPA/600/R-10/089.

von der Kammer F, Ferguson PL, Holden PA, Masion A, Rogers KR, Klaine SJ, Koelmans AA, Horne N, Unrine JM. 2012. Analysis of engineered nanomaterials in complex matrices (environment and biota): General considerations and conceptual case studies. Environmental Toxicology and Chemistry 31:32-49.

von Goetz N, Lorenz C, Windler L, Nowack B, Heuberger M, Hungerbuhler K. 2013a. Migration of Ag- and TiO2-(Nano)particles from Textiles into Artificial Sweat under Physical Stress: Experiments and Exposure Modeling. Environ Sci Technol 47:9979-87.

von Goetz N, Fabricius L, Glaus R, Weitbrecht V, Gunther D, Hungerbuhler K. 2013b. Migration of silver from commercial plastic food containers and implications for consumer exposure assessment. Food additives \& contaminants.Part A, Chemistry, analysis, control, exposure \& risk assessment 30:612-20.

Vorbau M, Hillemann L, Stintz M. (2009a). Method for the characterization of the abrasion induced nanoparticle release into air from surface coatings. J Aerosol Sci 40:209-217.

Vorbau M, Hillemann L, Stintz M. (2009b). Method for the characterization of the abrasion induced nanoparticle release into air from surface coatings. J Aerosol Sci 40:209-217.

WHO. 2013. Nanotechnology and human health: Scientific evidence and risk governance. Report of the WHO expert meeting 10-11 December 2012, Bonn, Germany. Copenhagen, WHO Regional Office for Europe. 
Wiesner MR, Lowry GV, Alvarez P, Dionysiou D, Biswas P. 2006. Assessing the risks of manufactured nanomaterials. Environ Sci Technol 40:4336-4345.

Wiesner MR, Lowry GV, Jones KL, Hochella J,Michael F., Di Giulio RT, Casman E, Bernhardt ES. 2009. Decreasing Uncertainties in Assessing Environmental Exposure, Risk, and Ecological Implications of Nanomaterials. Environ Sci Technol 43:6458-6462.

Windler L, Lorenz C, von Goetz N, Hungerbuhler K, Amberg M, Heuberger M, Nowack B. 2012. Release of Titanium Dioxide from Textiles during Washing. Environ Sci Technol 46:8181-8188.

Wohlleben W, Brill S, Meier MW, Mertler M, Cox G, Hirth S, von Vacano B, Strauss V, Treumann S, Wiench K. 2011. On the Lifecycle of Nanocomposites: Comparing Released Fragments and their In-Vivo Hazards from Three Release Mechanisms and Four Nanocomposites. Small 7:2384-2395.

Wohlleben W, Cox G, Hirth S, Meier MW, Wohlleben W, Vogel S, Landsiedel R, Tomovic Z. 2013. Elastic CNT-polyurethane nanocomposite: Synthesis, performance and assessment of fragments released during use. Nanoscale 5:369-380.

Yan Y, Yang H, Li J, Lu X, Wang C. 2012. Release behavior of nano-silver textiles in simulated perspiration fluids. Text Res J 82:1422-1429.

Zhou S, Wu L, Shen W, Gu G. 2004. Study on the morphology and tribological properties of acrylic based polyurethane/fumed silica composite coatings. J Mater Sci 39:1593-1600.

Zorita S, Olabarrieta J, Benguria P. 2013. Photocatalytic pavements: release of TiO2 nanoparticles during different aging processes. Abstract from 8th International Conference on the Environmental Effects of Nanoparticles and Nanomaterials. 
Zuin S, Gaiani M, Ferrari A, Golanski L. 2014. Leaching of nanoparticles from experimental water-borne paints under laboratory test conditions. Journal of nanoparticle research 16:1-17. 
Tables

Table 1: ECHA Chapter R.15 Consumer Exposure Estimation (ECHA, 2012) algorithms and their basic assumptions.

\begin{tabular}{|c|c|c|}
\hline Exposure & Algorithm & Assumptions \& Applications \\
\hline Inhalation & $\begin{array}{l}C_{\text {inh }}=\frac{Q_{\text {prod }} \cdot F c_{\text {prod }}}{V_{\text {room }}} \cdot 1000 \\
\text { R.15-1 } \\
D_{\text {inh }}=\frac{F_{\text {resp }} \cdot C_{\text {inh }} \cdot I H_{\text {air }} \cdot T_{\text {contact }}}{B W} \cdot n \\
\text { R.15-2 }\end{array}$ & $\begin{array}{l}\text { All substance is released as a gas, } \\
\text { vapor or airborne particulate. } \\
\text { Worst-case scenario: event duration } \\
\text { is } 24 \mathrm{~h} \text { and } 100 \% \text { of the substance } \\
\text { will be released into the room with } \\
\text { no ventilation. }\end{array}$ \\
\hline \multirow[t]{2}{*}{ Dermal A } & $\begin{array}{l}L_{\text {der }}=\frac{Q_{\text {prod }} \cdot F c_{\text {prod }}}{A_{\text {skin }}} \cdot 1000 \\
\text { R.15-3 } \\
D_{\text {der }}=\frac{Q_{\text {prod }} \cdot F c_{\text {prod }} \cdot n}{B W} \cdot 1000 \\
\text { R.15-4 }\end{array}$ & $\begin{array}{l}\text { All of the substance in the product } \\
\text { is directly applied to the skin (e.g. } \\
\text { liquid soap or sunscreen). Applies } \\
\text { for non-volatile substances } \\
\text { contained in a mixture. }\end{array}$ \\
\hline & $\begin{array}{l}C_{\text {der }}=\frac{C_{\text {prod }}}{D} \cdot 1000=\frac{R H O_{\text {prod }} \cdot F C_{\text {prod }}}{D} \cdot 1000 \\
\qquad=\frac{Q_{\text {prod }} \cdot F C_{\text {prod }}}{V_{\text {prod }} \cdot D} \cdot 1000 \\
\text { R.15-5 } \\
L_{\text {der }}=C_{\text {der }} \cdot T H_{\text {der }} \\
\text { R.15-6 } \\
D_{\text {der }}=\frac{L_{\text {der }} \cdot A_{\text {skin }} \cdot n}{B W} \\
\text { R.15-7 }\end{array}$ & $\begin{array}{l}\text { Certain body parts are dipped in a } \\
\text { mixture containing the substance. } \\
\text { Applies for non-volatile substances } \\
\text { contained in a mixture. }\end{array}$ \\
\hline Dermal B & $\begin{array}{l}L_{\text {der }}=\frac{Q_{\text {prod }} \cdot F c_{\text {prod }} \cdot F c_{\text {migr }} \cdot F_{\text {contact }} \cdot T_{\text {contact }}}{A_{\text {skin }}} \cdot 1000 \\
\text { R.15-8 } \\
L_{\text {der }}=S D_{\text {prod }} \cdot F c_{\text {prod }} \cdot F c_{\text {migr }} \cdot F_{\text {contact }} \cdot T_{\text {contact }} \\
\text { R.15-9 } \\
D_{\text {der }}=\frac{L_{\text {der }} \cdot A_{\text {skin }} \cdot n}{B W} \\
\text { R.15-7 }\end{array}$ & $\begin{array}{l}\text { Substance migrates from the area of } \\
\text { the article in contact with skin (e.g. } \\
\text { textiles). } \\
\text { Worst-case scenario: time of } \\
\text { contact } 24 \mathrm{~h} \text { and the skin contact } \\
\text { factor is set at } 1 \text {. }\end{array}$ \\
\hline Oral & 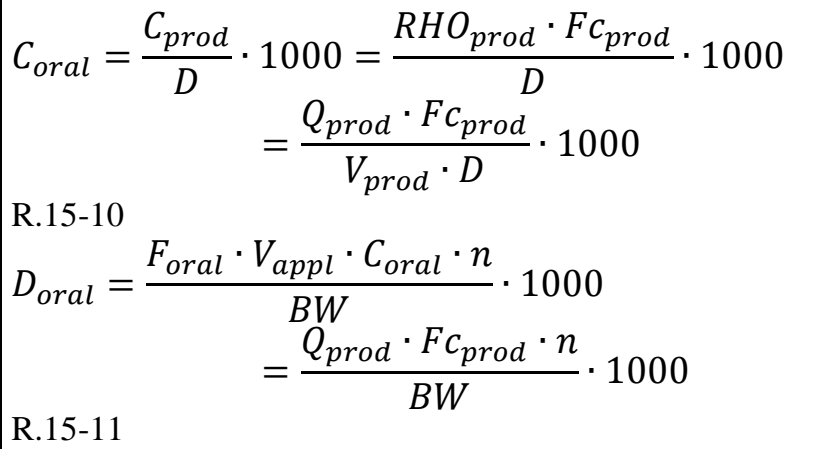 & $\begin{array}{l}\text { Substance in a product is } \\
\text { unintentionally swallowed during } \\
\text { normal use or substance is } \\
\text { migrating from an article e.g. due to } \\
\text { sucking, chewing or licking of toys, } \\
\text { children's books or textiles. } \\
\text { Model may also be used to estimate } \\
\text { exposure from ingestion of the non- } \\
\text { respirable fraction of inhaled } \\
\text { airborne particulates. }\end{array}$ \\
\hline
\end{tabular}


$\mathrm{Q}_{\text {prod }}-$ Amount of product used [g]; $\mathrm{Fc}_{\text {prod }}-$ Weight fraction of substance in product $\left[\mathrm{g} \cdot \mathrm{g}_{\text {prod }}{ }^{-1}\right] ; \mathrm{V}_{\text {room }}-$ Room size $\left(\right.$ default $\left.20 \mathrm{~m}^{3}\right)\left[\mathrm{m}^{3}\right] ; F_{\text {resp }}-$ Respirable fraction of inhaled substance (default $=1$ ) [-]; $I H_{\text {air }}-$ Ventilation rate of person $\left[\mathrm{m}^{3} \cdot \mathrm{d}^{-1}\right] ; \mathrm{T}_{\text {contact }}-$ Duration of contact per event (default 1 day) [d]; BW - Body weight $[\mathrm{kg}] ; \mathrm{N}$ - Mean number events per day $\left[\mathrm{d}^{-1}\right] ; C_{\text {prod }}-$ Concentration of substance in product before dilution $\left[\mathrm{g} \cdot \mathrm{cm}^{-3}\right]$; $\mathrm{D}$ - Dilution factor [-]; $\mathrm{RHO}_{\text {prod }}$ - Density of product before dilution $\left[\mathrm{g} \cdot \mathrm{cm}^{-3}\right] ; \mathrm{V}_{\text {prod }}$ - Volume of product used before dilution $\left[\mathrm{cm}^{3}\right] ; \mathrm{V}_{\mathrm{appl}}$ - Volume of diluted product actually contacting the skin $\left[\mathrm{cm}^{3}\right] ; \mathrm{TH}_{\mathrm{der}}-$ Thickness of product layer on skin (default $0.01 \mathrm{~cm}$ ) $[\mathrm{cm}] ; \mathrm{A}_{\text {skin }}$ - Surface area of the exposed skin $\left[\mathrm{cm}^{2}\right] ; \mathrm{F}_{\mathrm{cmigr}}$ - Rate (fraction) of substance migrating to skin per unit time $\left[\mathrm{g} \cdot \mathrm{g}^{-1} \cdot \mathrm{t}^{-1}\right] ; \mathrm{F}_{\text {contact }}$ - Fraction of contact area for skin, to account for the fact that the product is only partially in contact with the skin (default $=1)\left[\mathrm{cm}^{2} \cdot \mathrm{cm}^{-2}\right] ; \mathrm{SD}_{\text {prod }}$ - Surface density (mass per unit area) $\left[\mathrm{mg} \cdot \mathrm{cm}^{-2}\right] ; \mathrm{F}_{\text {oral }}$ - Fraction of $\mathrm{V}_{\text {appl }}$ that is ingested (default $\left.=1\right)[-] ; \mathrm{C}_{\text {inh }}-$ Concentration of substance in air of room $\left[\mathrm{mg} \cdot \mathrm{m}^{-3}\right] ; \mathrm{D}_{\mathrm{inh}}-$ Inhalatory dose (intake) of substance per day and body weight $\left[\mathrm{mg} \cdot \mathrm{kg}_{\mathrm{bw}}{ }^{-1} \cdot \mathrm{d}^{-1}\right] ; \mathrm{C}_{\mathrm{der}}$ - Dermal concentration of substance on skin $\left[\mathrm{mg} \cdot \mathrm{cm}^{-3}\right] ; \mathrm{L}_{\mathrm{der}}-$ Dermal load, amount of substance on skin area per event $\left[\mathrm{mg} \cdot \mathrm{cm}^{-2}\right] ; D_{\text {der }}$ - Dermal dose, amount of substance (external dose) that can potentially be taken up (account later for actual dermal absorption) per body weight $\left[\mathrm{mg} \cdot \mathrm{kg}_{\mathrm{bw}}{ }^{-1} \cdot \mathrm{d}^{-1}\right] ; \mathrm{C}_{\text {oral }}$ - Concentration in ingested product $\left[\mathrm{mg} \cdot \mathrm{m}^{-3}\right] ; \mathrm{D}_{\text {oral }}-$ Intake per day and body weight $\left[\mathrm{mg} \cdot \mathrm{kg}_{\mathrm{bw}}{ }^{-1} \cdot \mathrm{d}^{-1}\right]$ 


\section{Figures}

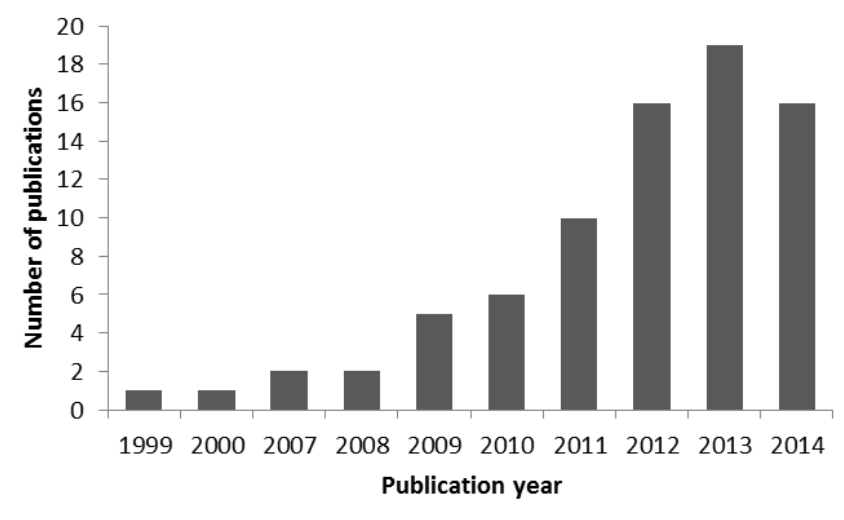

Figure 1: Published literature on release from ENM-containing solid nanocomposites.

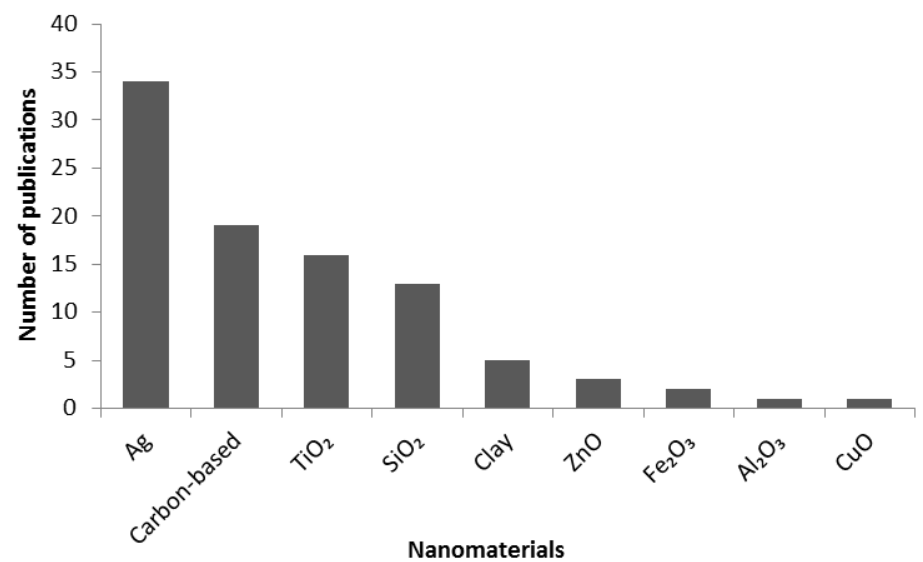

Figure 2: Published literature on release from ENM-containing solid nanocomposites, studies grouped by ENM composition. Publications addressing more than one ENM type are counted as one publication for each ENM addressed in the paper. 


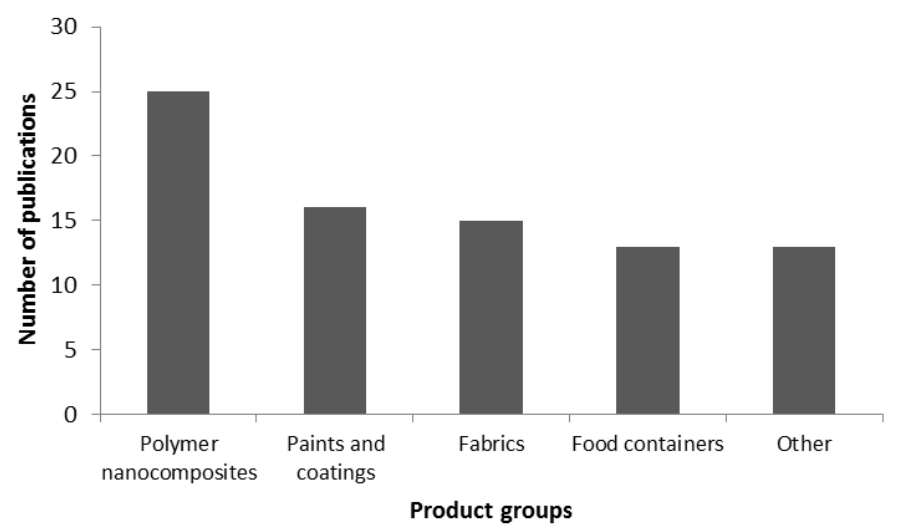

Figure 3: Published literature on release from ENM-containing solid nanocomposites, studies grouped by product groups used for experiments. 


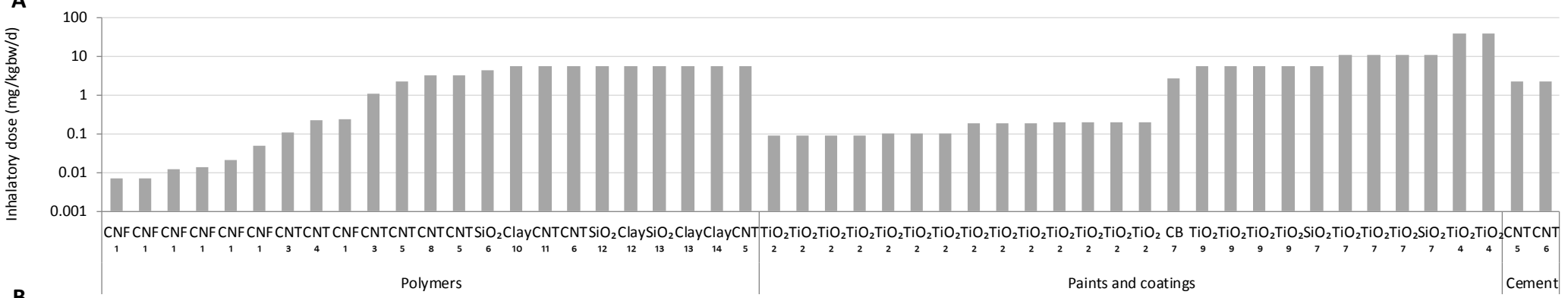

B Polymers

Paints and coatings

Cement

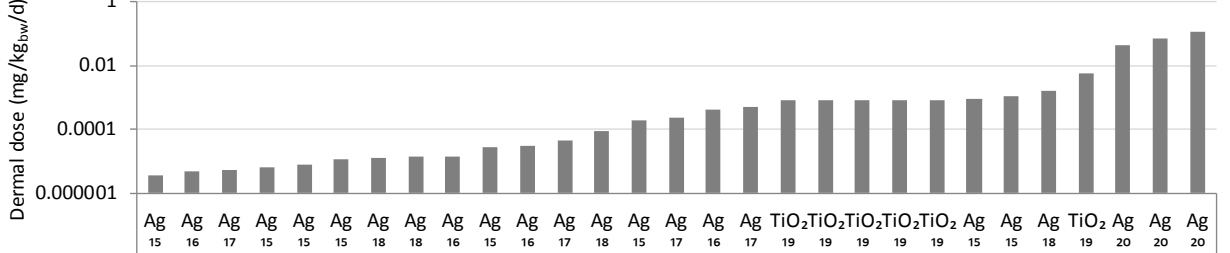

C

Fabrics, textiles and apparel

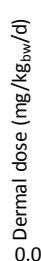

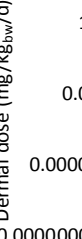

Fabics,

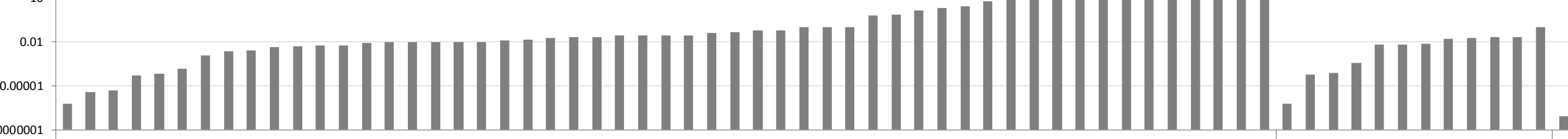

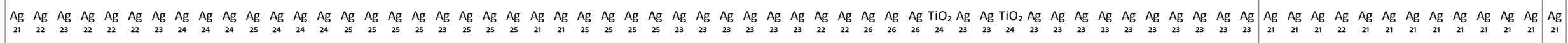

D

Fabrics, textiles and apparel

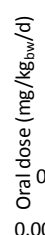

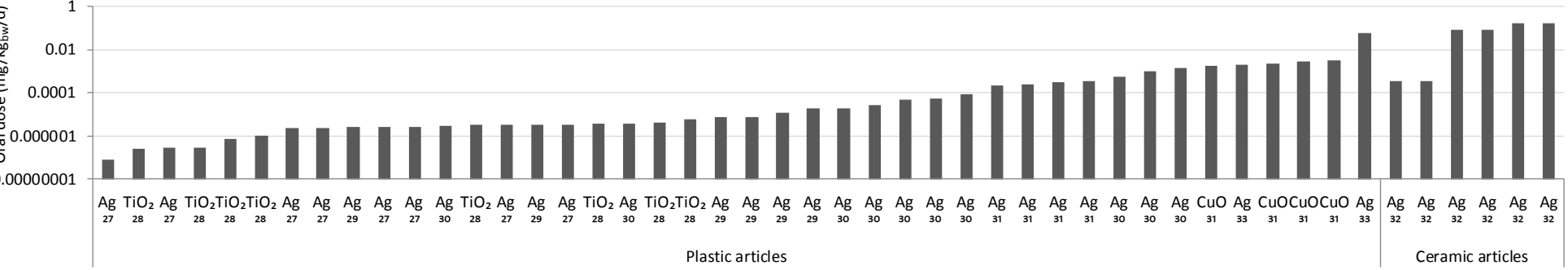


Figure 4: Exposure dose $\left(\mathrm{mg} / \mathrm{kg}_{\mathrm{bw}} / \mathrm{d}\right)$ calculation results using R.15 guidance document and data reported in literature for selected products and their corresponding ENM. A: Inhalatory dose estimation results; B: Dermal (scenario A - dipping hands in solution) dose estimation results; C: Dermal (scenario B - migration from an article directly on to the skin) dose estimation results; D: Oral dose estimation results. Assumptions and inputs can be found in Table S3a, S3b, S3c, S3d in Supporting Information.

${ }^{1}$ (Mazzuckelli et al., 2007), ${ }^{2}$ (Shandilya et al., 2014), ${ }^{3}$ (Schlagenhauf et al., 2012), ${ }^{4}$ (Gomez et al., 2014), ${ }^{5}$ (Hirth et al., 2013), ${ }^{6}$ (Wohlleben et al., 2011), ${ }^{7}$ (Koponen et al., 2011), ${ }^{8}$ (Wohlleben et al., 2013), ${ }^{9}$ (Hsu and Chein, 2007), ${ }^{10}$ (Sachse et al., 2012a), ${ }^{11}$ (Ogura et al., 2013), ${ }^{12}$ (Sachse et al., 2012b), ${ }^{13}$ (Sachse et al., 2013), ${ }^{14}$ (Raynor et al., 2012), ${ }^{15}$ (Geranio et al., 2009), ${ }^{16}$ (Mitrano et al., 2014), ${ }^{17}$ (Benn and Westerhoff, 2008),${ }^{18}$ (Lorenz et al., 2012), ${ }^{19}$ (Windler et al., 2012), ${ }^{20}$ (Pasricha et al., 2012), ${ }^{21}$ (Quadros et al., 2013), ${ }^{22}$ (Benn et al., 2010), ${ }^{23}$ (Kulthong et al., 2010), ${ }^{24}$ (von Goetz et al., 2013a), ${ }^{25}$ (Stefaniak et al., 2014), ${ }^{26}$ (Yan et al., 2012), ${ }^{27}$ (Artiaga et al., 2014), ${ }^{28}$ (Lin et al., 2014), ${ }^{29}$ (Hauri and Niece, 2011), ${ }^{30}$ (Cushen et al., 2014a), ${ }^{31}$ (Cushen et al., 2014b), ${ }^{32}$ (Ren and Smith, 2013), ${ }^{33}$ (Cushen et al., 2013) 


\section{Figure captions}

Figure 1: Published literature on release from ENM-containing solid nanocomposites.

Figure 2: Published literature on release from ENM-containing solid nanocomposites, studies grouped by ENM composition. Publications addressing more than one ENM type are counted as one publication for each ENM addressed in the paper.

Figure 3: Published literature on release from ENM-containing solid nanocomposites, studies grouped by product groups used for experiments.

Figure 4: Exposure dose $\left(\mathrm{mg} / \mathrm{kg}_{\mathrm{bw}} / \mathrm{d}\right)$ calculation results using R.15 guidance document and data reported in literature for selected products and their corresponding ENM. A: Inhalatory dose estimation results; B: Dermal (scenario A - dipping hands in solution) dose estimation results; C: Dermal (scenario B - migration from an article directly on to the skin) dose estimation results; D: Oral dose estimation results. Assumptions and inputs can be found in Table S3a, S3b, S3c, S3d in Supporting Information.

${ }^{1}$ (Mazzuckelli et al., 2007), ${ }^{2}$ (Shandilya et al., 2014), ${ }^{3}$ (Schlagenhauf et al., 2012), ${ }^{4}$ (Gomez et al., 2014), ${ }^{5}$ (Hirth et al., 2013), ${ }^{6}$ (Wohlleben et al., 2011), ${ }^{7}$ (Koponen et al., 2011), ${ }^{8}$ (Wohlleben et al., 2013), ${ }^{9}$ (Hsu and Chein, 2007), ${ }^{10}$ (Sachse et al., 2012a), ${ }^{11}$ (Ogura et al., 2013), ${ }^{12}$ (Sachse et al., 2012b), ${ }^{13}$ (Sachse et al., 2013), ${ }^{14}$ (Raynor et al., 2012), ${ }^{15}$ (Geranio et al., 2009), ${ }^{16}$ (Mitrano et al., 2014), ${ }^{17}$ (Benn and Westerhoff, 2008) ${ }_{1}^{18}$ (Lorenz et al., 2012), ${ }^{19}$ (Windler et al., 2012), ${ }^{20}$ (Pasricha et al., 2012), ${ }^{21}$ (Quadros et al., 2013), ${ }^{22}$ (Benn et al., 2010), ${ }^{23}$ (Kulthong et al., 2010), ${ }^{24}$ (von Goetz et al., 2013a), ${ }^{25}$ (Stefaniak et al., 2014), ${ }^{26}$ (Yan et al., 2012), ${ }^{27}$ (Artiaga et al., 2014), ${ }^{28}$ (Lin et al., 2014), ${ }^{29}$ (Hauri and Niece, 2011), ${ }^{30}$ (Cushen et al., 2014a), ${ }^{31}$ (Cushen et al., 2014b), ${ }^{32}$ (Ren and Smith, 2013), ${ }^{33}$ (Cushen et al., 2013) 